\title{
Ephrin-B2 controls PDGFRß internalization and signaling
}

\author{
Akiko Nakayama, ${ }^{1,2}$ Masanori Nakayama, ${ }^{1,2}$ Christopher J. Turner, ${ }^{3}$ Susanne Höing, ${ }^{4}$ \\ John J. Lepore, ${ }^{5,6}$ and Ralf H. Adams ${ }^{1,2,3,7}$ \\ ${ }^{1}$ Department of Tissue Morphogenesis, Max-Planck-Institute for Molecular Biomedicine, D-48149 Münster, Germany; ${ }^{2}$ Faculty \\ of Medicine, University of Münster, D-48149 Münster, Germany; ${ }^{3}$ Vascular Development Laboratory, Cancer Research UK, London \\ Research Institute, London WC2A 3PX, United Kingdom; ${ }^{4}$ Department Cell and Developmental Biology, Max-Planck-Institute \\ for Molecular Biomedicine, D-48149 Münster, Germany; ${ }^{5}$ Heart Failure Discovery Performance Unit, ${ }^{6}$ Metabolic Pathways \\ and Cardiovascular Therapeutic Area Unit, GlaxoSmithKline, King of Prussia, Pennsylvania 19406, USA
}

B-class ephrins, ligands for EphB receptor tyrosine kinases, are critical regulators of growth and patterning processes in many organs and species. In the endothelium of the developing vasculature, ephrin-B2 controls endothelial sprouting and proliferation, which has been linked to vascular endothelial growth factor (VEGF) receptor endocytosis and signaling. Ephrin-B2 also has essential roles in supporting mural cells (namely, pericytes and vascular smooth muscle cells [VSMCs]), but the underlying mechanism is not understood. Here, we show that ephrin-B2 controls platelet-derived growth factor receptor $\beta$ (PDGFR $\beta$ ) distribution in the VSMC plasma membrane, endocytosis, and signaling in a fashion that is highly distinct from its role in the endothelium. Absence of ephrin-B2 in cultured VSMCs led to the redistribution of PDGFR $\beta$ from caveolin-positive to clathrin-associated membrane fractions, enhanced PDGF-B-induced PDGFR $\beta$ internalization, and augmented downstream mitogenactivated protein (MAP) kinase and c-Jun N-terminal kinase (JNK) activation but impaired Tiam1-Rac1 signaling and proliferation. Accordingly, mutant mice lacking ephrin-B2 expression in vascular smooth muscle developed vessel wall defects and aortic aneurysms, which were associated with impaired Tiam1 expression and excessive activation of MAP kinase and JNK. Our results establish that ephrin-B2 is an important regulator of PDGFR endocytosis and thereby acts as a molecular switch controlling the downstream signaling activity of this receptor in mural cells.

[Keywords: PDGF; receptor; signaling; tyrosine kinase]

Supplemental material is available for this article.

Received June 10, 2013; revised version accepted October 23, 2013.

Cell surface receptors integrate numerous signals from the tissue environment and can thereby induce fundamental changes in cellular behavior, which are the basis of numerous growth, migration, and tissue patterning processes. Increasing evidence indicates that endocytosis not only regulates receptor levels and bioavailability in the plasma membrane but can also influence the strength and identity of downstream signal transduction events (Abella and Park 2009; Hansen and Nichols 2009; Kumari et al. 2010). The concept that receptor internalization and trafficking can regulate signal transduction events has been initially proposed for the epidermal growth factor receptor (Vieira et al. 1996), but, subsequently, similar findings have been reported for the receptors binding insulin growth factor, transforming growth factor $\beta, \mathrm{Wnt}$, or

\footnotetext{
7 Corresponding author

E-mail ralf.adams@mpi-muenster.mpg.de

Article is online at http://www.genesdev.org/cgi/doi/10.1101/gad.224089.113 Freely available online through the Genes \& Development Open Access option.
}

vascular endothelial growth factor (VEGF) (Chow et al. 1998; Di Guglielmo et al. 2003; Yu et al. 2007; Finger et al. 2008; Lanahan et al. 2010; Sawamiphak et al. 2010; Wang et al. 2010; Morcavallo et al. 2012).

Platelet-derived growth factor receptor $\beta$ (PDGFR $\beta$ ), a receptor tyrosine kinase (RTK) activated by PDGF, suppresses the differentiation and promotes the proliferation of vascular smooth muscle cells (VSMCs) and other mesenchymal cell types (Andrae et al. 2008; Olson and Soriano 2011). Signals induced by PDGF binding to PDGFR $\beta$ include the activation of Ras-mitogen-activated protein (MAP) kinase, phosphoinositide 3-kinase, the small GTPase Rac1, and c-Jun N-terminal kinase (JNK) (Andrae et al. 2008). Different membrane domains and endocytic pathways have been proposed to regulate

(C) 2013 Nakayama et al. This article, published in Genes \& Development, is available under a Creative Commons License (AttributionNonCommercial 3.0 Unported), as described at http://creativecommons. org/licenses/by-nc/3.0/. 
PDGFR $\beta$ function (Liu et al. 1996; Sundberg et al. 2009). Treatment of cultured human fibroblasts with dynamin inhibitors, which block clathrin-dependent endocytosis, argues for both dynamin-dependent and -independent PDGFR $\beta$ internalization processes (Sadowski et al. 2013). Caveolin-1 can interfere with PDGF-induced signal transduction (Fujita et al. 2004; Yamamoto et al. 2008), which suggests that lipid rafts or caveolae might harbor a passive RTK pool devoid of signaling activity. Recently, it also has been proposed that PDGFR $\beta$ endocytosis in cultured cells can be mediated by macropinocytosis involving dorsal, clathrin-containing membrane ruffles (Moes et al. 2012). However, the precise roles of different membrane domains for PDGFR $\beta$ function, the underlying molecular processes, and the regulation of downstream signal transduction responses remain incompletely understood.

Ephrins, membrane-anchored ligands for Eph family RTKs, are emerging as key regulators of endocytosis and trafficking processes (Bethani et al. 2010; Pitulescu and Adams 2010). In the developing cardiovascular system, ephrin-B2, a transmembrane protein belonging to the B-class ephrin subfamily, is an important regulator of endothelial cell behavior and blood vessel growth. This function was recently linked to the regulation of ligandinduced VEGF receptor (VEGFR) internalization from the plasma membrane, which enhances certain downstream signaling events such as MAP kinase activation (Lanahan et al. 2010; Sawamiphak et al. 2010; Wang et al. 2010). Ephrin-B2, like other ephrins, not only activates Eph RTKs (termed "forward" signaling) on adjacent cells but also has receptor-like ("reverse") signal transduction capacity that contributes to its role in VEGFR endocytosis (Sawamiphak et al. 2010; Wang et al. 2010; Nakayama et al. 2013). In addition to its functions in the endothelial monolayer of blood vessels, ephrin-B2 also controls the behavior of pericytes and VSMCs in the blood vessel wall. Targeting of ephrin-B2 (encoded by the gene Efnb2) in these perivascular cell types led to the formation of unstable blood vessels, hemorrhaging, and perinatal lethality (Foo et al. 2006). Many of these features resembled macroscopic defects observed in mutant mice lacking PDGF-B or PDGFR $\beta$ (Lindahl et al. 1997; Tallquist et al. 2003). However, the exact mechanistic role of ephrin-B2 in perivascular cells and possible links to PDGF signaling have not been explored so far.

\section{Results}

Vessel wall and signaling defects in VSMC-specific ephrin-B2 mutants

To circumvent the previously reported perinatal lethality of general mural cell-specific ephrin-B2 mutants (Foo et al. 2006), probably a consequence of pericyte defects, and inactivate the ligand specifically in VSMCs, we interbred mice carrying a loxP-flanked version of the $E f n b 2$ gene $\left(E f n b 2^{\text {lox/lox}}\right)$ (Grunwald et al. 2004) and SM22 $\alpha$-Cre transgenics (Lepore et al. 2005). While a fraction of the resulting $E f n b 2^{\Delta S M C}$ mutants were viable, reached adulthood, and were fertile, only $42 \%$ of the expected number (i.e., $10.7 \%$ instead of $25 \%$ ) was obtained at weaning age (Supplemental Fig. 1A). The absence of ephrin-B2 protein in mutant VSMCs was confirmed by immunostaining of Efnb2 $2^{\Delta \mathrm{SMC}}$ aorta sections (Fig. 1A). The body weight of 30- to 60-wk-old mutants was reduced compared with age-matched littermates (Supplemental Fig. 1B). In addition, adult $E f n b 2^{\Delta S M C}$ mice showed significant dilation of the aorta accompanied by reduced thickness of the aortic VSMC layer, which was most obvious for the aortic arch region (Fig. 1B,C; Supplemental Fig. 1C,D). The mutant tunica media appeared flattened, and the elastic lamella failed to show the wavy morphology observed in control aortae (Supplemental Fig. 1E). Consistent with the reduced thickness of the adult $E f n b 2^{\Delta S M C}$ vessel wall, VSMC number and proliferation were reduced in mutants at postnatal day 8 (P8) (Fig. 1D-F), whereas the number of apoptotic cells was not significantly changed (data not shown). Our previous characterization of mural cellspecific Efnb2 mutants had shown that loss of ephrin-B2 resulted in impaired association of pericytes and VSMCs with perinatal blood vessels (Foo et al. 2006). In addition to the aorta, VSMC-specific Cre activity in SM22 $\alpha$-Cre transgenic mice is detectable in the embryonic dermis and postnatal retinal vasculature (Supplemental Fig. 1F; data not shown). Accordingly, arterial smooth muscle cell coverage was reduced and irregular in $E f n b 2^{\Delta S M C}$ embryonic day 17.5 (E17.5) skin and P8 retina (Supplemental Fig. 1G,H; data not shown). In contrast, the (untargeted) pericytes in $E f n b 2^{\Delta S M C}$ mutants showed no overt differences from control littermates (Supplemental Fig. $1 \mathrm{H}$; data not shown).

To gain insight into the molecular changes associated with the vessel wall defects in $E f n b 2^{\Delta S M C}$ mutants in vivo, we investigated the activation status of key signaling pathways in adult mutant and littermate control aorta lysates. Activation of MAP kinase Erk1/2, JNK, and PDGFR $\beta$ was significantly increased in $E f n b 2^{\Delta S M C}$ aorta samples (Fig. 1G,J). In line with the reduced VSMC proliferation, Efnb2 ${ }^{\Delta S M C}$ lysates contained elevated levels of p2 $7^{\text {kip1 }}$, an inhibitor of G1-to-S-phase transition in the cell cycle (Bond et al. 2008), whereas the active, GTP-associated form of the small GTPase Rac1 was strongly reduced (Fig. 1H-J). Thus, loss of ephrin-B2 in vascular smooth muscle led to vessel wall defects and altered activation of multiple key signaling pathways in vivo.

\section{Regulation of Tiam1-Rac1 signaling by ephrin-B2}

To gain further insight into the functional role of ephrinB2 in VSMCs, we compared the gene expression profiles of previously generated control and Efnb2 knockout VSMCs (Foo et al. 2006) by Affymetrix microarray analysis. This revealed that loss of ephrin-B2 led to pronounced changes in gene expression (Supplemental Fig. 2A,B). One of the top down-regulated genes (49-fold reduction compared with control) was Tiam1, which encodes T-cell lymphoma invasion and metastasis-inducing protein 1 , a key regulator of cell morphology and polarity (Mertens et al. 2006). As Tiam1 is guanine nucleotide exchange factor (GEF) and thereby an activator of Racl, we reasoned 
A

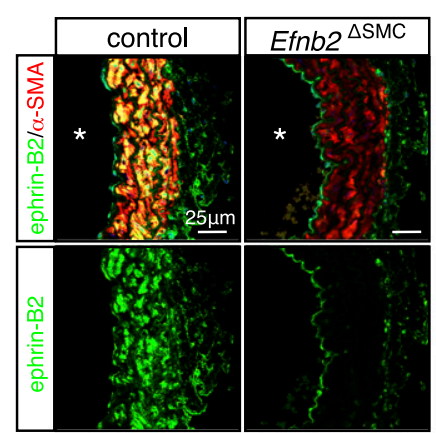

D

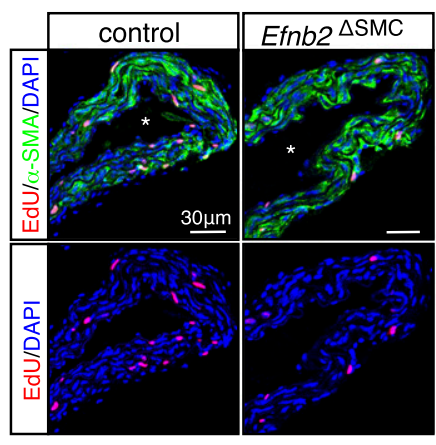

B

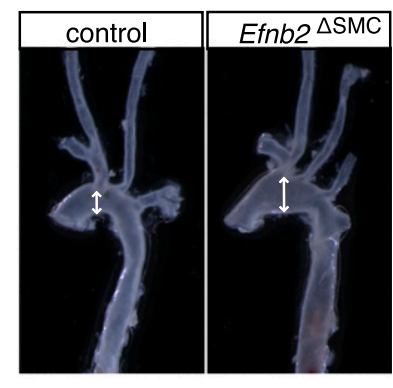

C

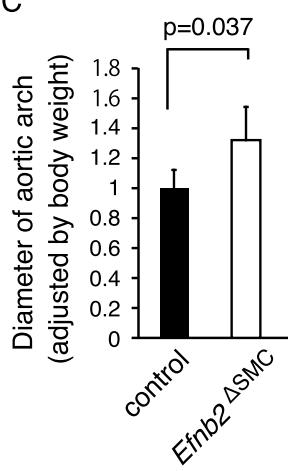

E

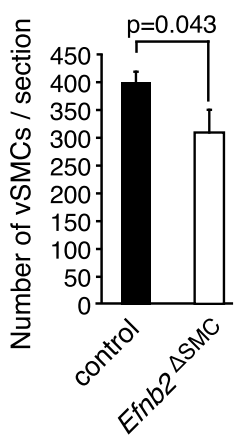

F

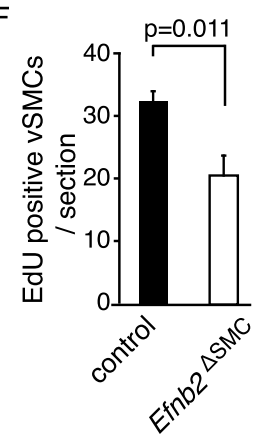

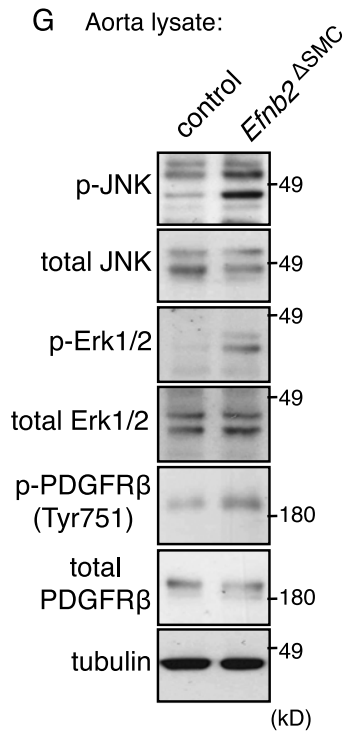

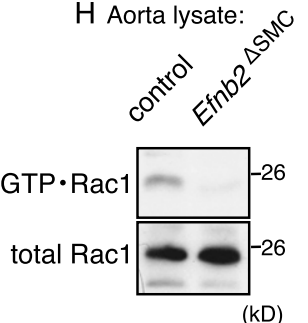

(kD)

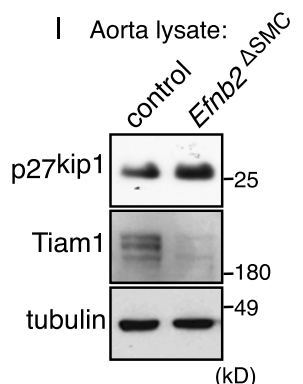

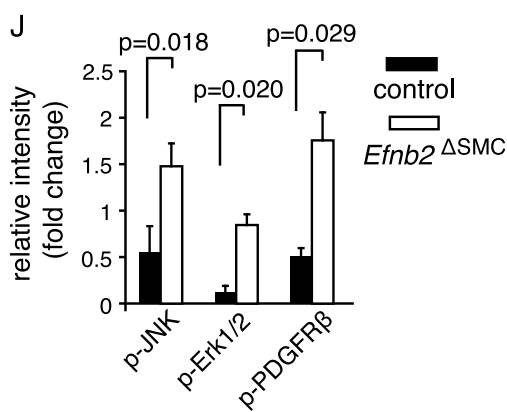

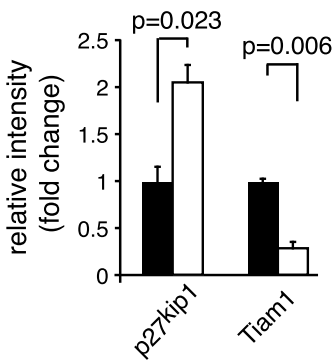

Figure 1. Vessel wall defects in smooth muscle cell-specific ephrin-B2 mutants. (A) Confocal images showing ephrin-B2 (green) and $\alpha$-smooth muscle actin $\left(\alpha\right.$-SMA; red) immunostaining on sections of adult (30 wk) control and Efnb2 ${ }^{\Delta S M C}$ mutant aortae. $\left({ }^{\star}\right)$ Vessel lumen. $(B)$ Dilation affecting freshly isolated adult Efnb2 ${ }^{\Delta S M C}$ aortic arches (right) compared with control littermates (left). Arrows indicate vessel diameter. $(C)$ Quantitation of relative aortic arch diameter of adult mice $(>30$ wk). $P$-value was calculated using twotailed Student's $t$-test $(n=4)$. Error bars indicate SD. $(D-F)$ 5-Ethynyl-2'-deoxyuridine (EdU) labeling (2-h pulse; red) of proliferating cells in control and mutant P8 aorta. (Green) $\alpha$-SMA; (blue) nuclei (DAPI). ${ }^{\star}$ ) Vessel lumen. Quantitation of total $\alpha$-SMA-positive cells $(E)$ and EdU-labeled VSMCs $(F)$. $P$-values were calculated using two-tailed Student's $t$-test $(n=3)$. Error bars indicate SD. $(G)$ Western blot analysis of total and phosphorylated JNK (p-JNK), Erk1/2 (p-Erk1/2), and PDGFR $\beta$ (p-PDFGR $\beta$ ) in control and Efnb2 ${ }^{\Delta S M C}$ aorta lysate, as indicated. Tubulin is shown as a loading control. Molecular weight markers (in kilodaltons) are indicated. $(H, I)$ Strongly decreased levels of active Racl (GTP.Rac1) in Efnb $2^{\Delta S M C}$ aorta lysate relative to control (shown in $H$ ). (I) Tiaml protein was nearly undetectable in mutant samples, whereas amounts of $\mathrm{p} 27^{\mathrm{kip} 1}$ were elevated. Tubulin is shown as a loading control. Molecular weight markers are indicated. (J) Quantitative analysis of band intensities in the Western blots shown in $H$ and $I$ and replicates. $P$-values were calculated using two-tailed Student's $t$-test $(n=3)$. Error bars indicate SD. 
that its down-regulation might be causally linked to the reduced Rac1 activity in Efnb2 ${ }^{\Delta S M C}$ aortas (Fig. 1H). Western blot analysis confirmed reduced Tiam 1 protein levels in $E f n b 2^{\Delta S M C}$ aorta lysate (Fig. 1I) as well as in cultured murine Efnb2 knockout VSMCs (Fig. 2A).

As both MAP kinase and Racl signaling play important roles in the regulation of smooth muscle cell proliferation (Zou et al. 1998; Bond et al. 2008), we next investigated the interplay between these two pathways. Inhibition of Rac1 by administration of the small compound NSC23766 significantly reduced proliferation of cultured VSMCs and led to up-regulation of p2 $7^{\mathrm{kip} 1}$ (Fig. 2B,C). VSMC proliferation was also slightly reduced and $\mathrm{p} 27^{\mathrm{kip} 1}$ proliferation was increased after overactivation of MAP kinase (Fig. 2B,C), which was achieved by expressing a Raf/ estrogen receptor (ER) fusion protein ( $\Delta$ Raf1-ER) with tamoxifen-inducible kinase activity (Thiel et al. 2009). Further reduction of VSMC mitosis was obtained after combined NSC23766 administration and $\Delta$ Raf1-ER activation (Fig. 2B), which resembled the low Racl activity but elevated phospho-Erk1/2 observed in Efnb2 ${ }^{\Delta S M C}$ aorta lysates (Fig. 1G,H). We reported previously that cultured Efnb2 knockout VSMCs display spreading defects (Foo et al. 2006), which can be mimicked by treatment of VSMCs with the Rac1 inhibitor NSC23766 (Fig. 2D,E; Supplemental Fig. 2C). Defective spreading of Efnb2 knockout cells was rescued by re-expression of full-length Tiam1 (Fig. 2D,E), which also significantly restored the proliferation of ephrin-B2-deficient VSMCs (Fig. 2F). Thus, ephrin-B2 is a critical regulator of Tiam1/Rac1 and thereby controls VSMC spreading and mitosis.

Next, we investigated the regulation of Tiam 1 expression by upstream signals. When control or Efnb2 knockout cells were treated with the Erk1/2 inhibitor U0126, Tiam1 expression was significantly increased at both the mRNA and protein levels (Fig. 2G,H). Conversely, Erk1/2 activation with tamoxifen-inducible $\Delta$ Rafl-ER reduced Tiam1 mRNA and protein in murine VSMCs (Fig. 2I,J). The regulation of Tiam1 by ephrin-B2 does not appear to be regulated by acute reverse signal transduction. While the stimulation of VSMCs with recombinant EphB4/Fc fusion protein led to detectable phosphorylation of B-class ephrins after 15 and $30 \mathrm{~min}$, there was no appreciable change in Tiam1 protein levels under the same conditions (Supplemental Fig. 2D). We showed previously that prolonged EphB4/Fc stimulation triggers pronounced internalization and degradation of ephrin-B2 after 2.5 and $6 \mathrm{~h}$ (Foo et al. 2006). The strong reduction of ephrin-B2 at these time points was accompanied by down-regulation of Tiam1 protein (Fig. 2K). This reduction of Tiam 1 was prevented by the addition of the proteasome inhibitor MG132 (Fig. $2 \mathrm{~K}, \mathrm{~L}$ ), which indicates a role of protein degradation in this process.

Together, these data strongly argue for positive regulation of Tiam1 in smooth muscle cells by ephrin-B2, whereas MAP kinase activity reduces Tiam1 expression. Accordingly, the combination of absent ephrin-B2 expression and elevated phospho-Erk1/2, as observed in mutant aorta lysates, can explain the lost expression of Tiam1 and low Racl activity in Efnb2 ${ }^{\Delta S M C}$ VSMCs.
Signaling defects in ephrin-B2-deficient VSMCs are linked to PDGFR $\beta$

An increasing body of evidence connects the Eph/ephrin system to the modulation of other cell surface receptors, such as VEGFRs in endothelial cells (Bethani et al. 2010; Pitulescu and Adams 2010). Given the prominent role of PDGF signaling in VSMCs and other cell types of the mesenchymal lineage (Andrae et al. 2008; Olson and Soriano 2011), we next investigated the role of ephrin-B2 in the regulation of PDGFR $\beta$. Stimulation of murine control VSMCs with PDGF-B led to transient autophosphorylation of PDGFR $\beta$, which was accompanied by JNK and Erk1/2 activation (Fig. 3A). In line with findings in $E f n b 2^{\Delta S M C}$ aorta lysates (Fig. 1G), PDGFR $\beta$ tyrosine phosphorylation as well as phospho-JNK and phosphoErk1/2 levels were substantially increased in Efnb2 knockout VSMCs at 5 and $15 \mathrm{~min}$ after PDGF-B treatment (Fig. 3A). In contrast, other factors triggering MAP kinase activation in VSMCs, such as insulin-like growth factor 1 (IGF-1) and tumor necrosis factor $\alpha$ (TNF- $\alpha$ ) (Hayashi et al. 1999; Yoshimura et al. 2005), led to comparable Erk1/2 phosphorylation in control and Efnb2 knockout VSMCs (Supplemental Fig. 3A). Thus, the modulatory role of ephrin-B2 is confined to certain growth factors but not others. Consistent with the strongly reduced Tiam1 expression in Efnb2 knockout cells, PDGF-B-induced activation of Racl was impaired in comparison with control VSMCs (Fig. 3B). However, NSC23766 treatment of cultured VSMCs did not result in appreciable alterations in PDGF-B-induced JNK and Erk1/2 phosphorylation, suggesting that the up-regulation of these signals in Efnb2 knockout cells is not a direct consequence of Tiam1/Rac1 defects (Supplemental Fig. 3B).

Since ephrin-B2 positively regulates VEGFR internalization and thereby promotes the downstream activation of MAP kinase and Rac1 in endothelial cells (Sawamiphak et al. 2010; Wang et al. 2010; Nakayama et al. 2013), we next investigated whether PDGFR $\beta$ function is modulated by ephrin-B2. Immunostaining of surface PDGFR $\beta$ in nonpermeablized murine VSMCs and surface biotinylation experiments indicated that PDGF-B-induced uptake of the receptor was accelerated in Efnb2 knockout cells relative to controls (Fig. 3C-F). The faster internalization of PDGFR $\beta$ in ephrin-B2-deficient cells was accompanied by more rapid degradation of the RTK (Fig. 3E). Moreover, strongly enhanced association of PDGFR $\beta$ with the clathrin heavy chain $(\mathrm{CHC})$ suggested that clathrinmediated endocytosis of this receptor might be enhanced in Efnb2 knockout VSMCs as well as in Efnb2 ${ }^{\Delta S M C}$ aorta lysate (Fig. 3G-I).

\section{Ephrin-B2 controls PDGFR $\beta$ distribution in the plasma membrane}

PDGFR $\beta$ distribution and endocytosis have been assigned to a number of different membrane domains, including clathrin-positive membrane ruffles, macropinosomes, and caveolae (Liu et al. 1996; Sundberg et al. 2009; Moes et al. 2012). To study the association of PDGFR $\beta$ with caveolin-1-positive or clathrin-containing membrane 
A

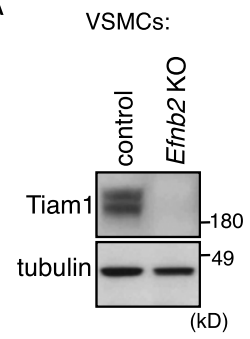

D

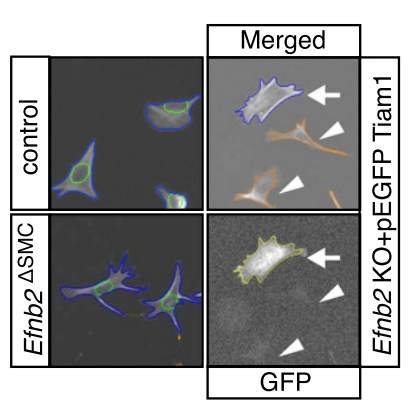

B

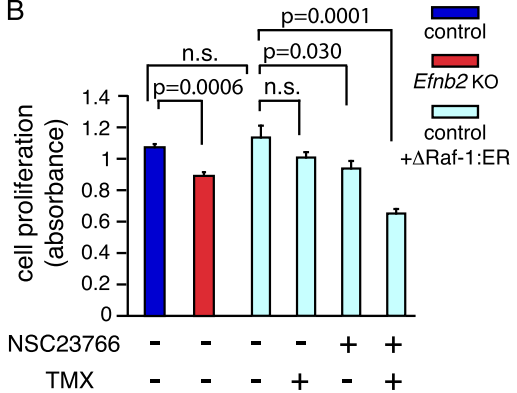

E

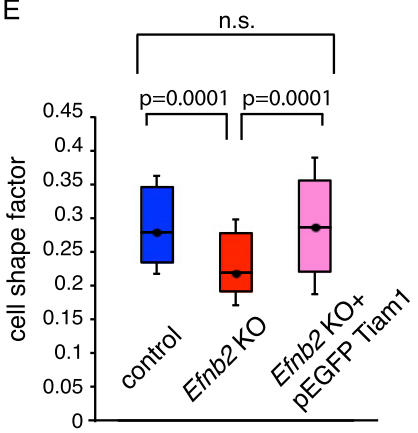

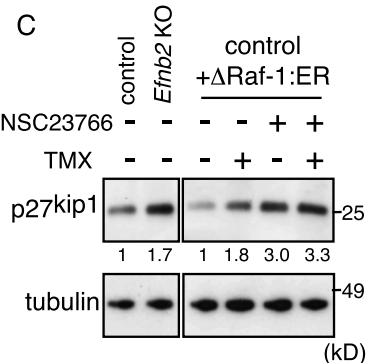

F

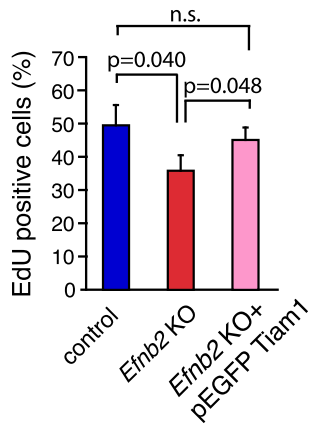

G

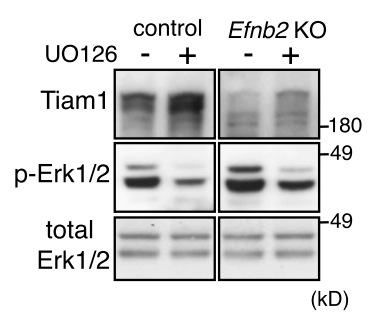

K

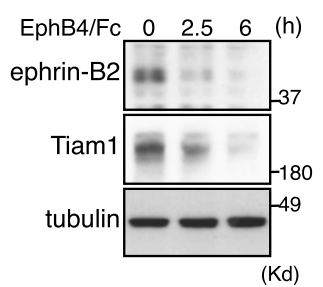

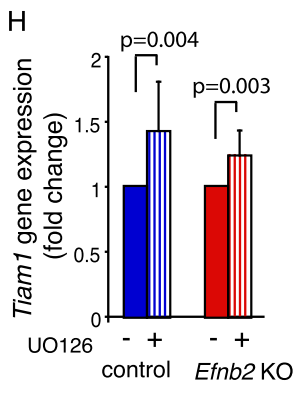

I

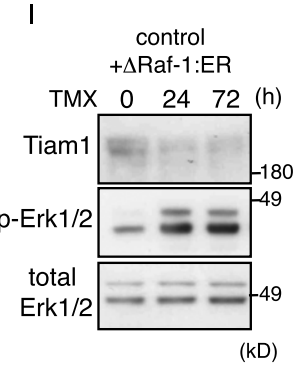

J

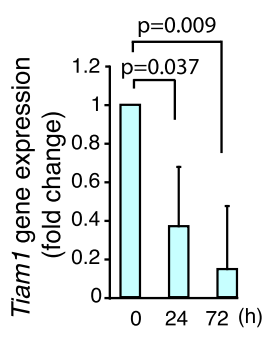

L

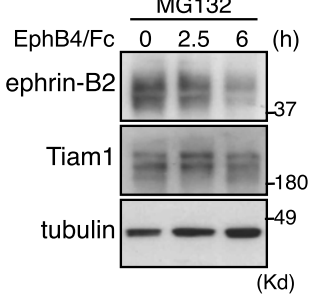

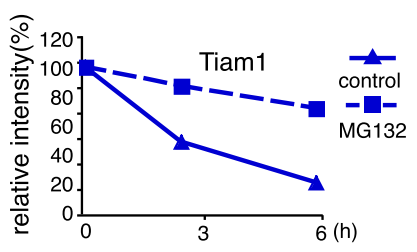

Figure 2. Regulation of VSMC proliferation by Tiam1-Rac1 and MAP kinase. $(A)$ Western blot showing strongly decreased Tiam1 protein levels in Efnb2 knockout VSMCs. Tubulin is shown as a loading control. Molecular weight markers are indicated. $(B)$ Cell proliferation (measured by the detection of cleaved tetrazolium salts) was reduced by Racl inhibitor (NSC23766) as well as simultaneous up-regulation of Erk1/2 activity ( $\Delta$ Rafl:ER+tamoxifen [TMX]). P-values were calculated using ANOVA with Tukey's post-hoc test $(n=3)$. Error bars indicate SD. $(C)$ Levels of the cell cycle inhibitor p $27^{\text {kip } 1}$ were increased by Racl inhibition and were not restored by Erk1/2 activation ( $\triangle$ Raf1:ER+TMX) in cultured murine VSMCs. Tubulin is shown as a loading control. Densiometric readings for p2 $7^{\text {kipl }}$ bands and molecular weight markers (in kilodaltons) are indicated. $(D)$ Images of automatic cell shape analysis. Phalloidin-stained VSMCs (blue) and DAPI-stained nuclei (green) were segmented. Arrows mark Efnb2 knockout cells that express pEGFP-Tiam1 (yellow); arrowheads in the images at the right indicate rejected cells due to undetectable GFP expression. (E) Box-andwhiskers diagram of shape factor data of $D$. A dot marks the median, the box spans $30 \%$ of the values, and whiskers span $50 \%$ of the values. $P$-values were calculated using ANOVA and Tukey's post-hoc test (control, $n=263$; knockout [KO], $n=263$; KO+pEGFP Tiam1, $n=232)$. Smaller shape factor of Efnb2 cells was rescued by re-expression of Tiam1. $(F)$ Re-expression of Tiam1 restored cell proliferation defects (measured by $2 \mathrm{~h}$ of EdU incorporation) in Efnb2 knockout smooth muscle cells. $P$-values were calculated using ANOVA $(n=3)$. Error bars indicate SD. $(G)$ Western blot showing increased Tiaml protein after Erk1/2 inhibition (U0126) for 24 h. Total Erk1/2 and p-Erk1/2 bands, which were strongly reduced by U0126, are shown below. (H) Quantitative PCR (qPCR) of Tiam1 expression in control or Efnb2 knockout VSMCs incubated with U0126 for 24 h. $P$-values were calculated using two-tailed Student's $t$-test $(n=3)$. Error bars indicate SD. $(I, J)$ Western blot $(I)$ and qPCR results $(J)$ showing reduced Tiam 1 levels after Erk1/2 activation $(\Delta$ Raf1:ER+TMX) for the indicated times. $P$-values were calculated using two-tailed Student's $t$-test $(n=3)$. Error bars indicate SD. (K) Tiam1 and ephrin-B2 protein levels were decreased after stimulation of VSMCs with EphB4/Fc for the indicated times (left), which was strongly reduced after administration of MG132 (right). (L) Densiometric analysis of data shown in $K$. 
A

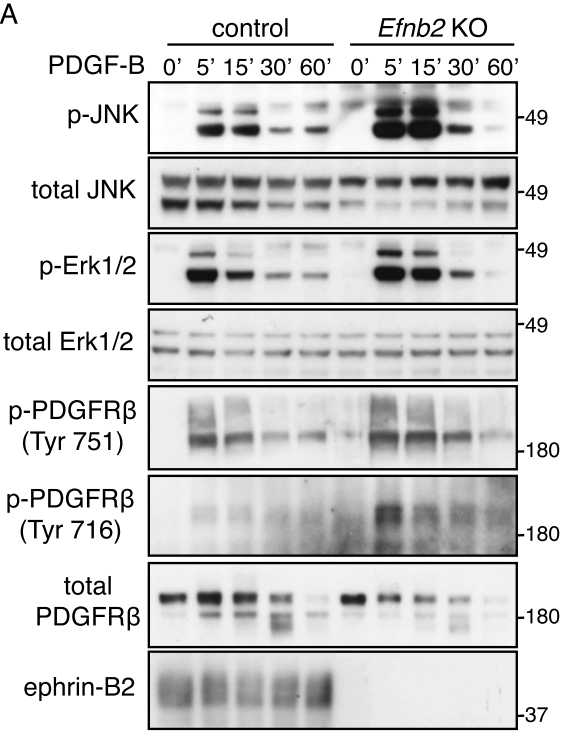

(kD)

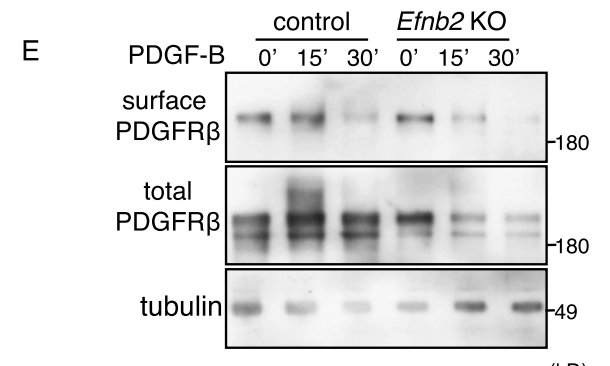

(kD)
G

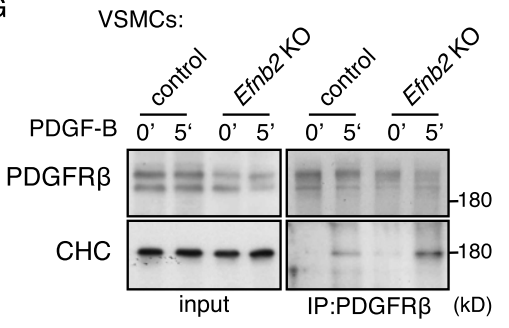

B

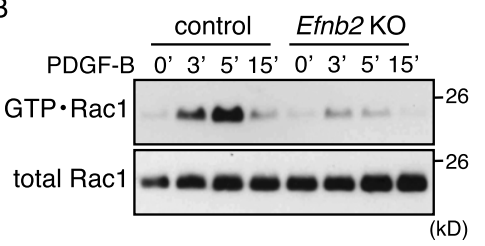

C

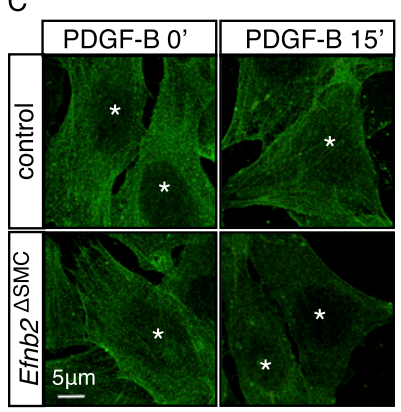

D

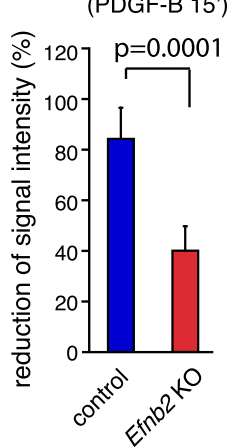

$\mathrm{F}$

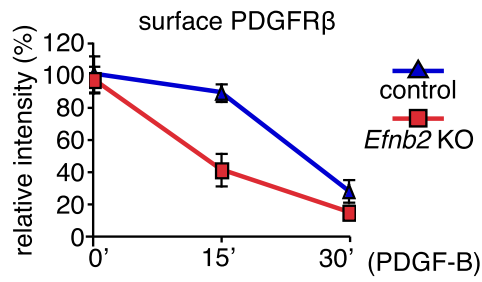

H Aorta lysate:

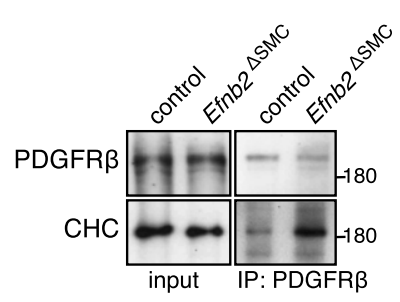

Figure 3. Ephrin-B2 negatively regulates PDGFR $\beta$ signaling and internalization. $(A)$ Western blot showing increased activation of JNK, Erk1/2, and PDGFR $\beta$ in PDGF-B-stimulated Efnb2 knockout compared with control VSMCs. (Bottom) Ephrin-B2 bands were absent in knockout cells. Molecular weight markers (in kilodaltons) are indicated at the right. (B) PDGF-B-induced activation of Rac1 (GTP • Rac1) was strongly diminished in Efnb2-deficient VSMCs. Time points after stimulation and molecular weight markers are indicated. Total Racl is shown as a loading control. $(C)$ Immunofluorescence on cultured VSMCs showing accelerated removal of cell surface PDGFR $\beta$ (green; nonpermeabilized cells) in Efnb2 knockout cells at $15 \mathrm{~min}\left(15^{\prime}\right)$ after PDGF-B stimulation. $\left({ }^{\star}\right)$ Nuclei. $(D)$ Statistical analysis of surface PDGFR $\beta$ signals shown in C. $P$-values were calculated using two-tailed Student's $t$-test $(n=5)$. Error bars indicate SD. $(E, F)$ Biochemical detection of surface (biotinylated) and total PDGFR $\beta$ in PDGF-B-stimulated control and Efnb2 knockout VSMCs $(E)$ and quantitation of band intensities (normalized to $\left.0^{\prime}\right)(F)$. (G) Western blot showing enhanced coimmunoprecipitation of CHC with PDGFR $\beta$ at 5 min after PDGF-B stimulation in cultured murine Efnb2 knockout and control cells. $(H, I)$ Western blot showing enhanced coimmunoprecipitation of CHC with PDGFR $\beta$ from $E f n b 2^{\Delta S M C}$ aorta lysate relative to control (shown in $H$ ). Input is shown at the left, and molecular weight markers (in kilodaltons) are indicated at the right. (I) Densiometric analysis of immunoprecipitated CHC. $P$-values were calculated using two-tailed Student's $t$-test $(n=3)$. Error bars indicate SD.

fractions, cultured murine VSMCs were analyzed by sucrose density gradient centrifugation. In the 11 fractions collected from control cells, ephrin-B2 and caveolin-1 were found together in fractions $3-6$, which also contained the vast majority of PDGFR $\beta$ (Fig. 4A). In Efnb2 knockout VSMCs, the distribution of caveolin-1 appeared unaltered, 
Nakayama et al.

A

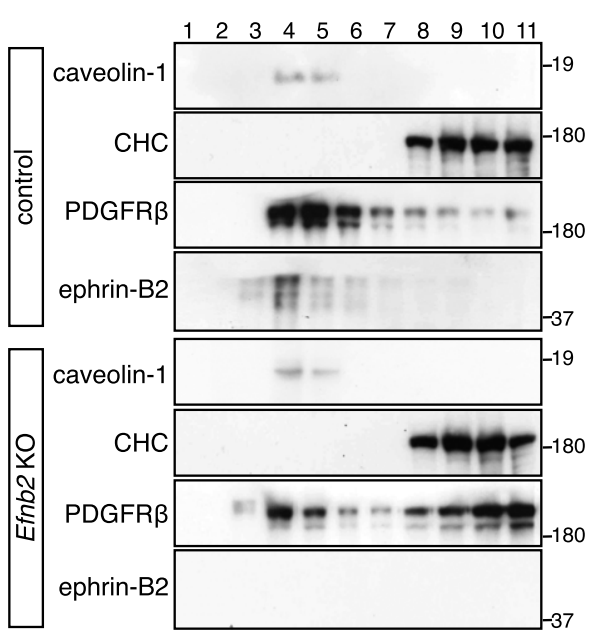

B

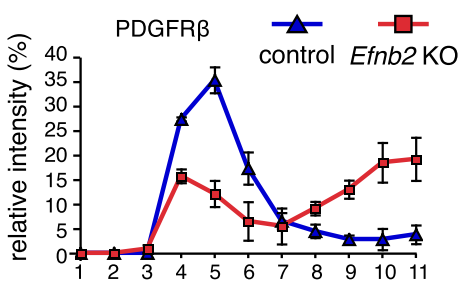

C

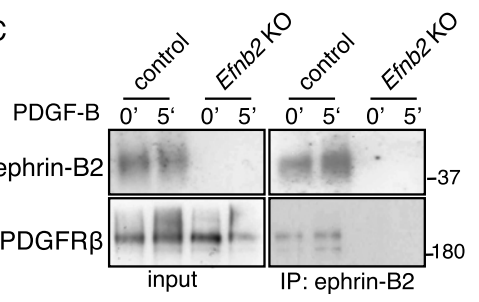

D

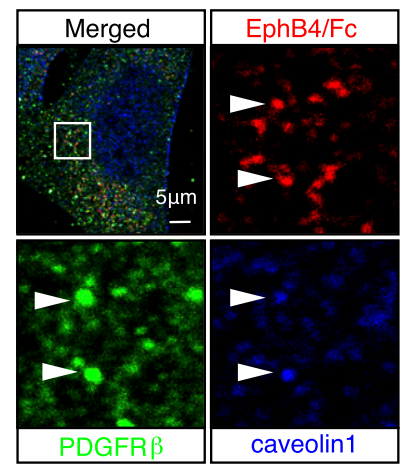

E

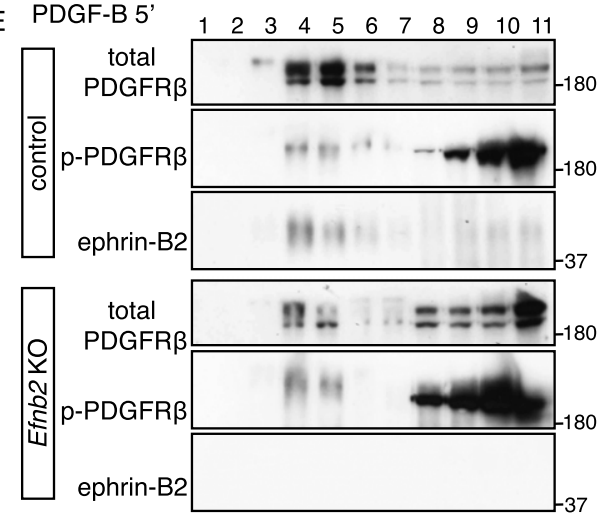

F

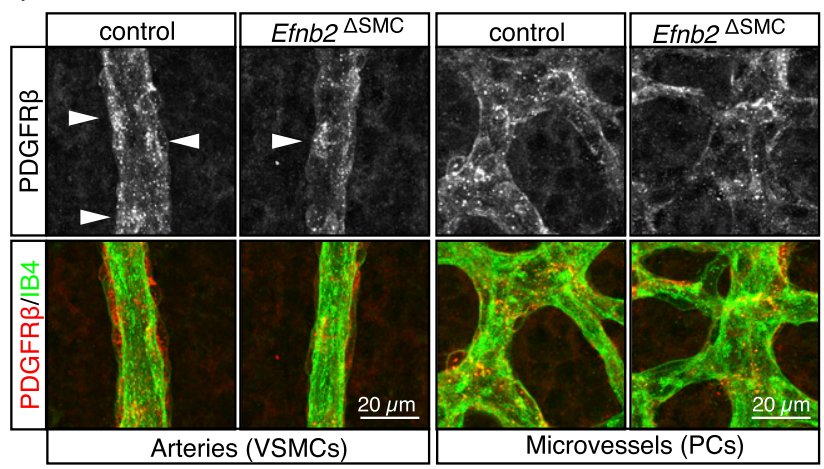

G

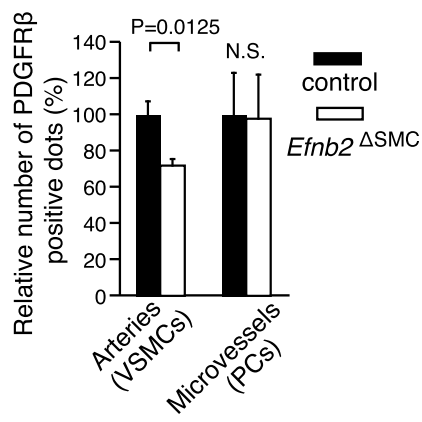

Figure 4. PDGFR $\beta$ membrane distribution depends on ephrin-B2. $(A, B)$ Sucrose density gradient centrifugation of membrane fractions from control and Efnb2 knockout cells (fractions 1-11, top to bottom of gradient). (A) Note redistribution of PDGFR $\beta$ from caveolin1-positive into CHC-containing fractions in Efnb2 knockout VSMCs. (B) Quantitation of PDGFR $\beta$ signals in fractions 1-11 (densiometric readings). Error bars indicate SD. $(C)$ Coimmunoprecipitation of PDGFR $\beta$ with ephrin-B2 (in sucrose gradient fractions 3-6) was enhanced after stimulation with PDGF-B (5') from control but not Efnb2 knockout cells. (D) Immunofluorescence of ephrinB2 (detected by EphB4/Fc; red), PDGFR $\beta$ (green), and caveolin-1 (blue). Individual channels of the insets are shown below the top panels. Arrowheads indicate colocalization of ephrin-B2, PDGFR $\beta$, and caveolin-1. (E) Sucrose density gradient fractionation of PDGF-B-stimulated control and Efnb2 knockout VSMCs. Note the predominant distribution of p-PDGFR $\beta$ bands in fractions 8-11, which was enhanced in the absence of ephrin-B2, whereas weak phosphorylation was associated with the bulk of PDGFR $\beta$ in fractions 4-6. $(F, G)$ The PDGFR $\beta$ immunosignal in VSMCs surrounding P8 retinal arteries is reduced in Efnb2 ${ }^{\Delta S M C}$ mutants relative to littermate controls, whereas comparable signals were seen in capillary perivascular cells (shown in $F$ ), which are not targeted by $S M 22 \alpha$-Cre transgenics. $(G)$ Quantitation of PDGFR $\beta$ immunosignals. $P$-values were calculated using two-tailed Student's $t$-test $(n=$ 3). Error bars indicate SD. 
while a significant portion of PDGFR $\beta$ had shifted to the bottom fractions (8-11) containing the $\mathrm{CHC}$ (Fig. 4A,B). Indicating association of ephrin-B2 and PDGFR $\beta$, both proteins were coimmunoprecipitated from the pooled sucrose gradient fractions 3-6 of cultured control but not Efnb2 knockout VSMCs (Fig. 4C). Arguing further for an ephrin-B2-dependent sequestering of PDGFR $\beta$ into caveolin-1-containing membrane fractions, immunofluorescence showed that signals for ephrin-B2 (detected by binding of EphB4/Fc), PDGFR $\beta$, and caveolin-1 overlapped in spot-like structures in cultured control VSMCs (Fig. 4D). In contrast, EphB4/Fc binding was absent in ephrin-B2-deficient cells, and little or no overlap was seen between PDGFR $\beta$ and caveolin-1 signals (Supplemental Fig. 4A).

PDGF-B-induced tyrosine phosphorylation and therefore activation of PDGFR $\beta$ was almost exclusively associated with the CHC-containing fractions $8-11$, while the vast majority of total PDGFR $\beta$ protein remained in fractions 4-6 and showed only weak tyrosine phosphorylation (Fig. 4E). In Efnb2 knockout cells, a significantly larger fraction of PDGFR $\beta$ was located in fractions 8-11, and only this pool showed substantial and, compared with the control, enhanced tyrosine phosphorylation (Fig. 4E). Likewise, phospho-Erk1/2 and JNK were found in fractions 8-11 after sucrose gradient centrifugation (Supplemental Fig. 4B). The notion that PDGFR $\beta$ signaling is associated with clathrin-mediated endocytosis was further supported by nystatin treatment of murine VSMCs. This inhibitor, which binds to cholesterol and disrupts caveolae-mediated endocytosis (Sakane et al. 2010), did not compromise PDGFR $\beta$ internalization but enhanced phosphorylation of PDGFR $\beta$, JNK, and Erk $1 / 2$ in response to PDGF-B (Supplemental Fig. 4C,D).

Taken together, the above results argue that PDGFR $\beta$ signaling activity is primarily linked to the clathrin pathway in VSMCs. Ephrin-B2 interacts with PDGFR $\beta$ and directs the receptor into caveolin-1-containing membrane domains, which negatively control clathrin-mediated PDGFR $\beta$ endocytosis as well as downstream activation of INK and MAP kinase. Further supporting that ephrin-B2 indeed counteracts clathrin-mediated PDGFR $\beta$ internalization and degradation not only in vitro (Fig. 3E,G), PDGFR $\beta$ immunostaining was significantly reduced in Efnb2 $2^{\Delta S M C}$ retinal arterial smooth muscle cells in vivo (Fig. 4F,G). Providing an internal control, anti-PDGFR $\beta$ signals in the untargeted pericytes were comparable in control and mutant retinas (Fig. 4F,G).

Given the important role of ephrin-B2 in internalization processes in endothelial cells, we tested whether the ligand might also direct the distribution of VEGF receptors to specific membrane domains. However, sucrose density gradient centrifugation of cultured murine endothelial cells failed to reveal overt alterations in VEGFR3 distribution in the absence of ephrin-B2 (Supplemental Fig. 4E,F).

\section{Role of Eph-ephrin interactions}

To investigate whether the loss of ephrin-B2 reverse signaling or the lack of ligand-induced (forward) EphB acti- vation was responsible for the observed smooth muscle cell defects, we stimulated cultured VSMCs with ephrin$\mathrm{B} 2 / \mathrm{Fc}$ or EphB4/Fc fusion proteins. Remarkably, the stimulation of ephrin-B2 with EphB4/Fc not only triggered the internalization of ephrin-B2 but also led to pronounced clustering and endocytosis of surface PDGFR $\beta$ (Fig. 5A,B; Supplemental Fig. 5A). In contrast, the stimulation of EphB receptors with recombinant ephrin-B2/Fc had no overt effect on PDGFR $\beta$ (Fig. 5A; data not shown). The EphB4/ Fc-induced internalization of PDGFR $\beta$ was not accompanied by appreciable tyrosine phosphorylation of the PDGFR and was largely unaffected by nystatin treatment (Fig. 5B,C). Nystatin also had no substantial effect on EphB4/Fc-induced ephrin-B2 internalization, which argues against a crucial role of caveolae in this process (Fig. 5B,C). PDGFR $\beta$ showed a substantial level of colocalization with EphB4/Fc fusion protein in VSMCs at different time points after stimulation (Fig. 5D; Supplemental Fig. 5B). Further supporting a role in PDGFR $\beta$ internalization, a fraction of the EphB4/Fc-positive (i.e., ephrin-B2) and PDGFR $\beta$ positive spots overlapped with EEA1, a marker of early endosomes (Fig. 5D). Likewise, sucrose density gradient centrifugation confirmed that PDGFR $\beta$ protein was shifted into CHC-containing fractions (8-11) at $30 \mathrm{~min}$ after EphB4/Fc stimulation (Fig. 5E). Following EphB4/Fc treatment and concomitant with the removal of ephrin-B2 from the cell surface, PDGF-B-mediated phosphorylation of PDGFR $\beta$ and Erk1/2 was gradually increased (Fig. 5F; Supplemental Fig. 5C), which resembled the enhanced activation of these molecules in Efnb2 knockout VSMCs (Fig. 3A). In contrast, no appreciable alteration in Erk1/2 activation was seen in cultured cells treated with ephrinB2/Fc (Supplemental Fig. 5D,E).

We showed previously that cultured and freshly isolated VSMCs express the receptors EphB2, EphB3, and EphB4, all of which can interact with ephrin-B2 (Foo et al. 2006). The data above indicate that interactions with the local microenvironment, such as neighboring EphB receptor-presenting smooth muscle cells, can alter ephrinB2 surface presentation and thereby strongly influence PDGFR $\beta$ internalization and signaling in VSMCs. Specifically, ephrin-B2-expressing cells that encounter high levels of EphBs in their direct environment would down-regulate Tiam1 and thereby Rac1 signaling (Fig. 2K), whereas PDGFR $\beta$ endocytosis as well as MAP kinase and JNK activation are concomitantly enhanced. We therefore propose that both the nature and quantity of signal transduction processes downstream from PDGFR $\beta$ are critically controlled by ephrin-B2 and its interactions with EphB receptors.

\section{Discussion}

\section{Ephrin-B2 modulates PDGFR $\beta$ activity}

RTKs can activate a variety of downstream signal transduction processes, leading to very different cellular behaviors, such as proliferation, migration, differentiation, or cell shape modulation. Previous work has shown that coreceptors, which interact with RTKs at the cell surface, 
A

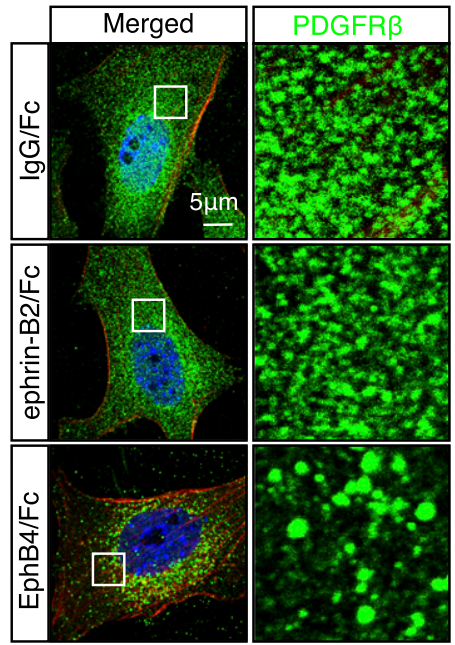

B

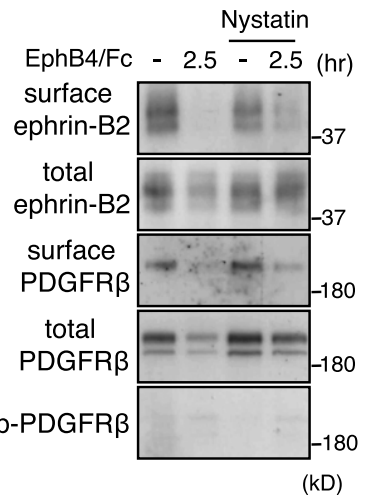

C

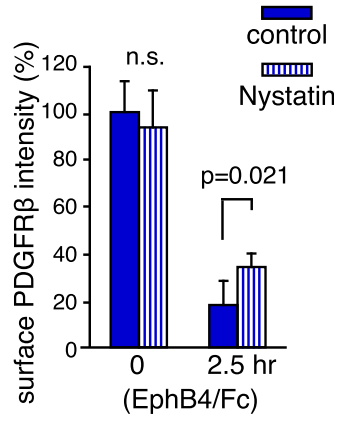

D
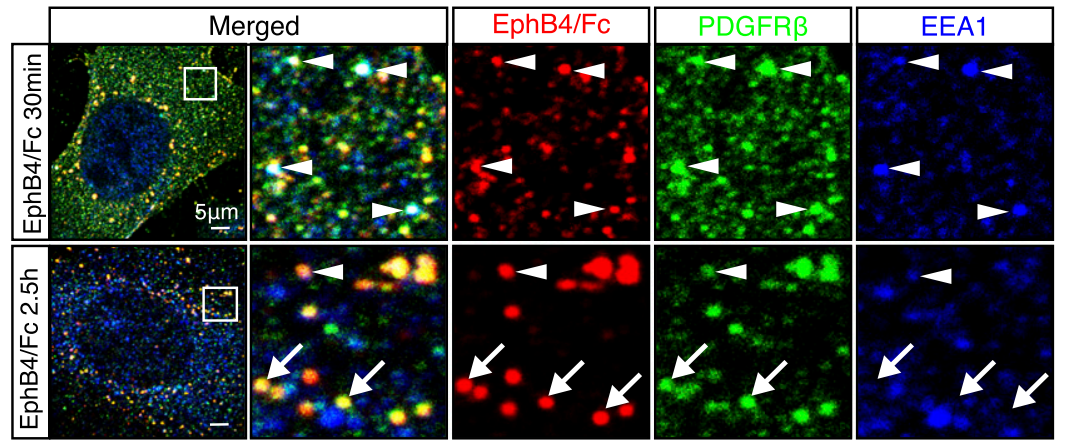

E

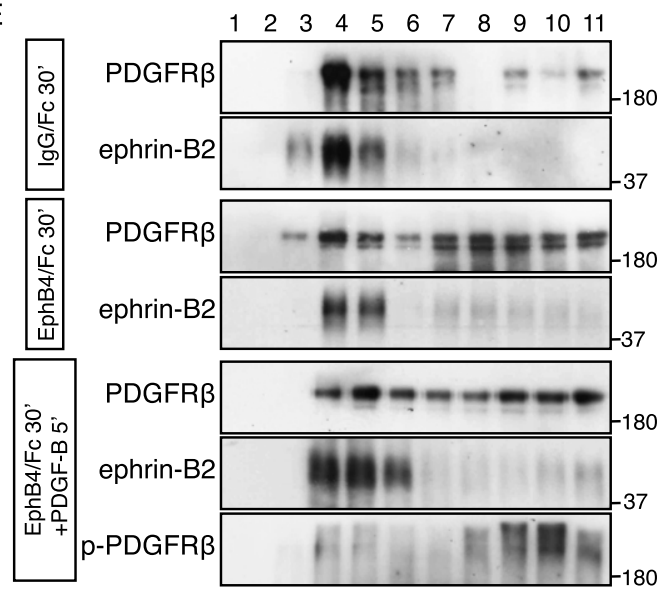

F
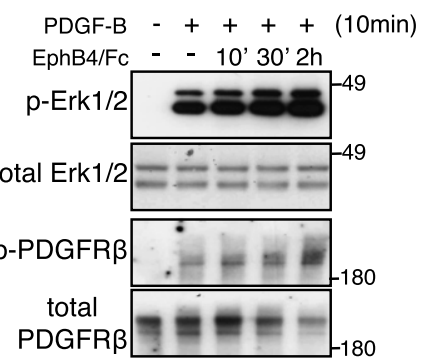

(kD)

(kD)

Figure 5. Eph-ephrin binding triggers PDGFR $\beta$ internalization. $(A)$ Indirect immunofluorescence of PDGFR $\beta$ (green) in cultured murine VSMCs stimulated with IgG/Fc, ephrin-B2/Fc, or EphB4/Fc for $2 \mathrm{~h}$, as indicated. (Red) Actin (phalloidin); (blue) nuclei (DAPI). Note accumulation of PDGFR $\beta$ in perinuclear structures resembling vesicles after EphB4/Fc but not ephrin-B2/Fc treatment. The panels at the right show higher magnification of the insets. (B) Western blot showing reduction of biotinylated (surface) ephrin-B2 and PDGFR $\beta$ in cultured murine VSMCs treated with EphB4/Fc. Nystatin treatment had a mild effect on EphB4/Fc-induced PDGFR $\beta$ and ephrin-B2 internalization. $(C)$ Densiometric analysis of biotinylated (surface) PDGFR $\beta$ shown in $B$. $P$-values were calculated using twotailed Student's $t$-test $(n=3)$. Error bars indicate SD. $(D)$ Immunofluorescence of ephrin-B2 (detected by EphB4/Fc binding; red), PDGFR $\beta$ (green), and EEA1 (blue) in murine VSMCs at 0.5 and $2.5 \mathrm{~h}$ after EphB4/Fc treatment. Higher magnifications of the insets in the left images are shown in the other panels. Arrowheads indicate colocalization (white) of ephrin-B2, PDGFR $\beta$, and EEA1 in early endosomes; arrows mark ephrin-B2 ${ }^{+}$and PDGFR $\beta^{+}$but EEA1 ${ }^{-}$structures. (E) Sucrose density gradient centrifugation of VSCMs at 30 min after stimulation with IgG/Fc, EphB4/Fc, or EphB4/Fc+PDFG-B, as indicated. EphB4/Fc triggered redistribution of PDGFR $\beta$ from fractions 4-7 into fractions 8-11. Active PDGFR $\beta$ (P-PDGFR $\beta$ ) at 5 min after stimulation with PDGF-B was associated with fractions 811. Molecular weight markers (in kilodaltons) are indicated. $(F)$ Western blot showing that Erk1/2 and PDGFR $\beta$ phosphorylation in PDGF-B-stimulated VSMCs (10 min) was enhanced by pretreatment with EphB4/Fc for the indicated times. Total Erk1/2 and PDGFR $\beta$ levels and molecular weight markers (in kilodaltons) are shown. Statistical analysis of p-Erk1/2 is provided in Supplemental Fig. 5C. 
can strongly influence their activity and integrate different signals from the local tissue environment. For example, low-density lipoprotein (LDL) receptor-related protein 1 (LRP1) - a transmembrane protein that can bind ligands as diverse as lipoproteins, proteases, growth factors, cytokines, and matrix proteins-associates with PDGFR $\beta$ and modulates its expression, internalization, and signaling (Boucher et al. 2003; Lehti et al. 2009; Muratoglu et al. 2010). Some controversy surrounds the exact role of LRP1 in PDGFR $\beta$ function, and it has been proposed that it can suppress (Boucher et al. 2003; Zhou et al. 2009) or support (Muratoglu et al. 2010) MAP kinase activation. LRP6, another member of the LDL receptor-related protein family, can also interact with PDGFR $\beta$, promote its degradation, and reduce PDGF-induced VSMC proliferation (Keramati et al. 2011). Neuropilin-1, a coreceptor for VEGFs in endothelial cells, has been found in VSMCs, where it promotes PDGF-induced smooth muscle cell migration. This is thought to involve an interaction with PDGFR $\alpha$, the second member of the PDGFR family (Pellet-Many et al. 2011). Here, we identified ephrin-B2 as a novel interaction partner of PDGFR $\beta$, which modulates the membrane distribution, internalization from the cell surface, and signaling activity of this RTK (Fig. 6). Our data suggest that PDGFR $\beta$-expressing cells can have very different signaling outputs in response to PDGF depending on the presence and expression levels of ephrin-B2. In particular, the absence of ephrin-B2 strongly enhances PDGF-Binduced MAP kinase and JNK activation, whereas Tiam1/ Rac1 signaling, a pathway critical for cell migration, proliferation, and spreading, gets diminished. Thus, ephrin-B2 can act as a molecular switch for different downstream signals induced by PDGF-B/PDGFR $\beta$.

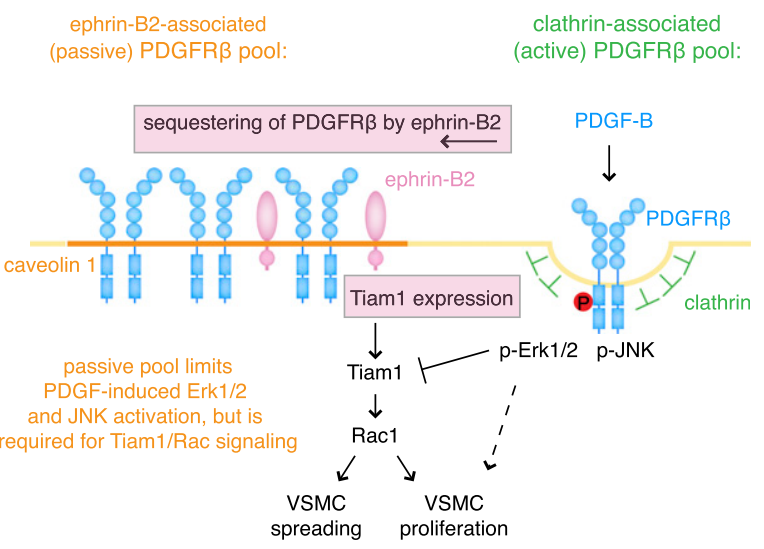

Figure 6. Schematic summary of findings. Ephrin-B2 sequesters PDGFR $\beta$ into caveolin-1-positive membrane domains and thereby counteracts clathrin-mediated endocytosis and excessive activation of the RTK. In particular, this process limits PDGF-Binduced Erk1/2 and JNK activation. Accordingly, down-regulation of ephrin-B2 levels (for example, via EphB-induced internalization through interactions with other VSMCs) enhances Erk1/2 and JNK signaling in response to PDGF-B. At the same time, ephrinB2 positively regulates Tiam 1 expression and thereby PDGF-Binduced Racl activation. MAP kinase overactivation reduces Tiaml transcript levels and protein, which leads to impaired smooth muscle cell spreading and proliferation.

\section{Ephrin-B2 and surface receptor internalization}

Members of the large Eph/ephrin gene families appear to be expressed in virtually all cell types and tissues, which raises the question of how a large but nevertheless limited set of ligand-receptor interactions can be translated into highly diverse biological responses. An increasing body of evidence indicates that the functional versatility of Eph/ ephrin molecules is achieved by molecular cross-talk with receptors from other families and, in particular, the modulation of their surface availability, clustering, trafficking, and endocytosis (Bethani et al. 2010; Pitulescu and Adams 2010). Among the surface molecules that are controlled by ephrin-B2, the VEGFRs VEGFR2 and VEGFR3 are most similar to PDGFR $\beta$ because all three RTKs share a similar organization of several extracellular immunoglobulin domains and a single cytoplasmic kinase domain and are evolutionarily closely related to Drosophila PVR (PDGF/ VEGF receptor). While previous work has revealed that ephrin-B2 controls VEGFR2 and VEGFR3 internalization and signaling activity in vitro and in vivo, it is remarkable that these processes are positively regulated by the ephrin, which is the opposite of what we observed for PDGFR $\beta$. It is currently unclear whether these differences reflect distinct molecular properties of PDGFRs and VEGFRs, cell type-specific features distinguishing endothelial cells and VSMCs, or the influence of ephrin-associated or independently acting additional regulators. Therefore, it will be important to identify the relevant molecular interaction partners of ephrin-B2 and PDGFR $\beta$ in caveolin-positive membrane domains as well as in the clathrin uptake machinery. Our findings also highlight that the precise role of ephrin-B2 in the modulation of other surface receptors can be complex and follow distinct mechanistic principles.

\section{Potential disease relevance}

Our data indicate that ephrin-B2 is a critical regulator of PDGF-B-induced signaling responses in vascular smooth muscle. While the phosphorylation of JNK and MAP kinase were strongly enhanced in Efnb2 mutant aortae and cultured cells, the expression of the GEF Tiam 1 and activation of Racl were diminished. These changes were associated with diminished VSMC proliferation and vessel wall defects in $E f n b 2^{\Delta S M C}$ mutants. While future work will have to address whether ephrin-B2 might be relevant in the context of VSMC-associated human diseases such as aortic aneurysms, our results suggest that the levels or availability of ephrin-B2 at the cell surface could potentially affect a variety of pathobiological processes involving PDGFs and their receptors (Ostman and Heldin 2007; Andrae et al. 2008). Examples include the autocrine and cell-autonomous PDGF-B/PDGFR $\beta$ signaling that promotes glioma growth and invasiveness in the brain (Uhrbom et al. 1998) or the PDGF-B overexpression in experimental cancer models, which induces the recruitment of vessels and stromal fibroblasts (Forsberg et al. 1993). High levels of PDGF expression and PDGFR signaling have been also associated with atherosclerotic lesions, and the administration of neutralizing antibodies and 
aptamers can reduce smooth muscle cell proliferation and neointima formation in mice (Raines 2004; Andrae et al. 2008). PDGF-B/PDGFR $\beta$ signaling in hepatic stellate cells, renal fibroblasts, and myofibroblasts has been linked to fibrosis in the liver, kidney, and skin, respectively (Andrae et al. 2008). As these examples highlight the great clinical relevance of the PDGF pathway, it should be worthwhile to investigate whether the presence or absence of ephrin-B2, related B-class ephrins, or the corresponding EphB receptors might alter PDGFR $\beta$ surface availability, internalization, and signaling in pathological settings. Likewise, it remains to be resolved whether therapeutic modulation of ephrin-B2 expression might be beneficial in disease processes involving dysregulated PDGF-B/PDGFR $\beta$ activity.

\section{Materials and methods}

\section{Loss-of-function genetics}

SM22 $\alpha$-Cre (Lepore et al. 2005) mice were bred with Efnb2 conditional mice (Grunwald et al. 2004). Cre ${ }^{+/-} E f n b 2$ lox/+ males were subsequently crossed with Efnb2 lox/lox females for experimental breedings. Cre-negative littermates were used as controls. Animals were in a mixed $129 \times \mathrm{C} 57 \mathrm{Bl} / 6$ genetic background. For examination of Cre activity, SM22 $\alpha$-Cre mice were bred to Rosa26-EYFP Cre reporter transgenics (Srinivas et al. 2001) and analyzed at the indicated stages.

All animal experiments were performed in compliance with the relevant laws and institutional guidelines and were approved by local animal ethics committees.

\section{Tissues and sections}

For staining of retinas, eyes were removed and, for $\alpha$-smooth muscle actin ( $\alpha$-SMA) staining, fixed in $4 \%$ paraformaldehyde (PFA) for $2 \mathrm{~h}$ at room temperature and dissected. For NG2 or PDGFR $\beta$ immunostaining, the PFA fixation was performed for $2 \mathrm{~h}$ on ice. Then, retinas were permeabilized and blocked in $1 \%$ BSA (Sigma, A4378) and $0.3 \%$ Triton X-100 overnight at $4{ }^{\circ} \mathrm{C}$ with gentle rocking. Next, retinas were washed three times in Pblec buffer $\left(1 \mathrm{mM} \mathrm{CaCl}_{2}, 1 \mathrm{mM} \mathrm{MgCl}, 1 \mathrm{mM} \mathrm{MnCl}_{2}, 1 \%\right.$ Triton X-100 in PBS) and incubated with biotinylated IB4 (1:25; Vector Laboratories, B-1205, Griffonia simlicifolia lectin I) overnight at $4{ }^{\circ} \mathrm{C}$ with gentle rocking. Retinas were washed five times with $0.5 \%$ BSA and $0.15 \%$ Triton X-100 and incubated with Alexa Fluor-coupled streptavidin (1:100; Invitrogen ) in blocking buffer for $2 \mathrm{~h}$ at room temperature. Other primary antibodies diluted in blocking buffer were applied overnight at $4^{\circ} \mathrm{C}$ : $\alpha$-SMA (1:400; Sigma, A2547), NG2 (1:100; Millipore, AB5320), and PDGFR $\beta$ (1:100; eBioscience, 14-1402). After a washing step, retinas were incubated with the corresponding Alexa Fluorcoupled secondary antibody (1:500; Invitrogen) in blocking buffer for $2 \mathrm{~h}$ at room temperature. Retinas were flat-mounted using Fluromount-G (SouthernBiotech, 0100-01).

For whole-mount staining of embryonic skin, back skin samples were dissected in PBS and fixed with $4 \%$ PFA for $2 \mathrm{~h}$ at $4^{\circ} \mathrm{C}$. After washing with PBS, skins were permeabilized and blocked in blocking buffer (1\% BSA [Sigma, A4378], 0.5\% Tween 20 in PBS) overnight at $4{ }^{\circ} \mathrm{C}$ with gentle rocking. Primary antibodies diluted in blocking buffer were applied overnight at $4^{\circ} \mathrm{C}$ : $\alpha$-SMA (1:400; Sigma, A2547), NG2 (1:100; Millipore, AB5320), and PECAM-1 (1:50; Becton Dickinson, 553371). After a washing step, skins were incubated with the corresponding Alexa Fluor-coupled secondary antibody (1:500; Invitrogen) in blocking buffer for $4 \mathrm{~h}$ at room temperature. Skins were flat-mounted using Fluromount-G (SouthernBiotech, 0100-01).

For staining of paraffin sections of aorta, sections were deparaffinized and incubated in $1 \%$ hydrogen peroxide for $10 \mathrm{~min}$ after antigen unmasking. Then, sections were blocked with $5 \%$ goat serum in PBS (30 min at room temperature) prior to incubation with Cy3-conjugated anti- $\alpha$-SMA antibody (1:400; Sigma, A2547) diluted in the blocking solution in combination with TO-PRO3 (1:1000; Invitrogen). Elastin was detected by autofluorescence on paraffin after staining with Cy3-conjugated anti$\alpha \mathrm{SMA}$ antibody. Detection of ephrin-B2 on paraffin sections was performed with goat anti-ephrin-B2 antibodies (1:200; R\&D Systems, AF496) as previously described (Batlle et al. 2002) in combination with Cy3-conjugated anti- $\alpha$-SMA antibody $(1: 400$; Sigma, A2547). For the labeling of proliferating cells, P8 pups received intraperitoneal injections with 5-ethynyl-2'-deoxyuridine (EdU; dissolved $2 \mathrm{mg} / \mathrm{mL}$ in PBS; Invitrogen). After $2 \mathrm{~h}$, pups were humanely sacrificed, and aortas were dissected and fixed for $1 \mathrm{~h}$ on ice and paraffin-embedded. After anti- $\alpha$-SMA-Cy 3 staining, EdU was detected with a Click-iT EdU Alexa Fluor 647 imaging kit (Invitrogen) according to the manufacturer's instructions and counterstained with DAPI.

For Western blotting, aorta lysates were prepared in lysis buffer $(0.1 \%$ SDS, $1 \%$ Triton X-100, $150 \mathrm{mM} \mathrm{NaCl}, 25 \mathrm{mM}$ Tris- $\mathrm{HCl}$ at $\mathrm{pH} 7.5,5 \mathrm{mM}$ EDTA-NaOH at $\mathrm{pH} 8.5,100 \mathrm{mM} \mathrm{NaF}$, $10 \mathrm{mM} \mathrm{Na}_{4} \mathrm{P}_{2} \mathrm{O}_{7}, 1 \mathrm{mM} \mathrm{Na}_{3} \mathrm{VO}_{4}$, protease inhibitor cocktail [1:100; Sigma, P2714]) by using a tissue homogenizer (UltraTurrax, IKA). The following antibodies were used: phosphoSAPK/JNK (1:1000; Cell Signaling, 9251), SAPK/JNK (1:1000; Cell Signaling, 9252), PDGFR $\beta$ (1:1000; Cell Signaling, 3169), phospho-PDGFR $\beta$ (Tyr751; 1:1000; Cell Signaling, 3161), phospho-PDGFR $\beta$ (Tyr716; 1:1000; ABNOVA, PAB1241), phosphop44/42 MAPK (1:1000; Cell Signaling, 9106), p44/42 MAPK (1:1000; Cell Signaling, 9102), p2 $7^{\text {kipl }}$ (1:1000; Becton Dickinson, 610242), Tiam1 (1:200; R\&D Systems, AF5038), and tubulin (1:2000; Sigma, T3526).

\section{Immunofluorescence}

Control and Efnb2 knockout cells were plated on glass coverslips, washed in PBS, fixed in 4\% PFA for $10 \mathrm{~min}$ on ice, washed in PBS, permeabilized with blocking buffer containing $0.1 \%$ Triton X-100 for $10 \mathrm{~min}$, and incubated in blocking buffer (1\% BSA in PBS) for $1 \mathrm{~h}$ at room temperature. Primary antibodies in blocking buffer were incubated overnight. Antibodies used were directed against PDGFR $\beta$ (1:50 dilution; R\&D Systems, AF1042), caveolin-1 (1:250; Becton Dickinson, 610493), or EEA1 (1:250; Abcam, ab2900). The cells were then washed three times for $10 \mathrm{~min}$ with PBS and incubated with appropriate secondary antibodies covalently linked to Alexa Fluor 488 or Alexa Fluor 546 (1:500) for $1 \mathrm{~h}$ at room temperature in PBS and counterstained with Alexa Fluor 546-conjugated anti-phalloidin antibody and/or DAPI (1:1000; Sigma). To detect PDGFR $\beta$ on the surface of cultured VSMCs, cells were incubated with anti-PDGFR $\beta$ antibody without permeabilization. The number of PDGFR $\beta$ signals in $1 \mu \mathrm{m}^{2}$ was calculated from five cells from each group; three independent experiments were performed. To visualize ephrin-B2 in cultured VSMCs, $5 \mathrm{mg} / \mathrm{mL}$ EphB4/Fc (R\&D Systems, 466-B4) was incubated with blocking solution. After washing with PBS, cells were incubated with Cy3-conjugated anti-human IgG/Fc (1:500; Jackson Laboratories, 109-165-008). For the labeling of proliferating cells, cultures were incubated with EdU (dissolved $10 \mu \mathrm{M}$ in culture medium; Invitrogen) for $2 \mathrm{~h}$ before staining. EdU was detected with a Click-iT EdU Alexa Fluor 647 imaging kit (Invitrogen) according to the manufacturer's instructions. 
Images were recorded with a Leica SP5 confocal microscope and Volocity software (Improvision).

\section{Cell stimulation experiments}

Control (Efnb2 lox/lox) and Efnb2 knockout cells were seeded at a density of $3.0 \times 10^{5}$ in $6-\mathrm{cm}$ dishes and incubated for $24 \mathrm{~h}$. After overnight serum starvation, cells were then incubated in serumfree growth medium containing $10 \mathrm{ng} / \mathrm{mL}$ PDGF-B (R\&D Systems, catalog no. 520-BB), 2 ng/mL IGF (Peprotech, 100-11), or 10 $\mathrm{ng} / \mathrm{mL}$ TNF- $\alpha(\mathrm{R} \& \mathrm{D}$ Systems, $2279-\mathrm{BT})$ at $37^{\circ} \mathrm{C}$ for the indicated times; collected with $300 \mu \mathrm{L}$ of $1 \times$ SDS sample buffer; and subjected to immunoblotting with antibodies binding phosphop44/42 MAPK (1:1000; Cell Signaling, 9106), p44/42 MAPK (1:1000; Cell Signaling, 9102), phospho-SAPK/JNK (1:1000; Cell Signaling, 9251), SAPK/JNK (1:1000; Cell Signaling, 9252), PDGFR $\beta$ (1:1000; Cell Signaling, 3169), phospho-PDGFR $\beta$ (Tyr751; 1:1000; Cell Signaling, 3161), phospho-PDGFR $\beta$ (Tyr716; 1:1000; ABNOVA, PAB1241), ephrin-B2 (1:1000; Sigma, HPA008999), Tiam1 (1:1000; R\&D Systems, AF5038), or tubulin (1:2000; Sigma, T5168). For stimulation with ephrin-B2-Fc (R\&D Systems, 496-EB) and EphB4-Fc fusion proteins (R\&D Systems, 466-B4), cells were treated with $5 \mu \mathrm{g} / \mathrm{mL}$ preclustered Fc fusion protein after serum starvation. Preclustering was achieved using $0.2 \mu \mathrm{g}$ of goat anti-human IgG antibody (Jackson Laboratories, 109-005-098) per microgram of Fc (at a concentration of $10 \mu \mathrm{g} / \mathrm{mL}$ ) for $30 \mathrm{~min}$ at room temperature. For proteasome inhibition experiments, cells were incubated with $10 \mu$ M MG-132 (Calbiochem, 474791) for $30 \mathrm{~min}$ before stimulation.

Cell proliferation was measured by using the Premix WST-1 cell proliferation assay system (Takara, MK400) according to the manufacturer's instructions. Briefly, $0.1 \times 10^{4}$ cells per well were cultured in microtiter plates (tissue culture grade, 96 wells, flat bottom) in a final volume of $100 \mu \mathrm{L}$ of culture medium per well. After the incubation period ( $48 \mathrm{~h}), 10 \mu \mathrm{L}$ of Premix WST-1 was added per well, and cells were incubated for $1-4 \mathrm{~h}$. The absorbance of the samples against a background control (the same volume of culture medium and Premix WST-1) was measured by using a microtiter plate (ELISA) reader.

\section{Cell surface biotinylation}

Cell surface biotinylation was performed on control and Efnb2 knockout cells (100-mm-diameter dishes). Surface receptors were labeled with $0.5 \mathrm{mg} / \mathrm{mL}$ sulpho-NHS-LC-biotin (Thermo Scientific) according to the manufacturer's instructions. After quenching of excess biotin with $100 \mathrm{mM}$ glycine in PBS, cells were dissolved in $0.8 \mathrm{~mL}$ of lysis buffer $(25 \mathrm{mM}$ Tris- $\mathrm{HCl}$ at $\mathrm{pH}$ 7.5, $150 \mathrm{mM} \mathrm{NaCl}, 5 \mathrm{mM}$ EDTA-NaOH at $\mathrm{pH} 8.5,1 \%$ NP-40, $100 \mathrm{mM} \mathrm{NaF}, 10 \mathrm{mM} \mathrm{Na}{ }_{4} \mathrm{P}_{2} \mathrm{O}_{7}, 1 \mathrm{mM} \mathrm{Na} \mathrm{VO}_{4}$, protease inhibitor cocktail [1:100; Sigma, P2714]). The lysates were precipitated with streptavidin agarose beads (Invitrogen), and precipitates were analyzed by immunoblot with anti-PDGFR $\beta$ antibody (1:1000 dilution; R\&D Systems, catalog no. 3169) or anti-ephrin-B2 antibody (1:1000; Sigma, HPA008999). For disruption of lipid rafts, cells were treated with $50 \mu \mathrm{g} / \mathrm{mL}$ nystatin for $30 \mathrm{~min}$ before stimulation.

\section{Sucrose density gradient centrifugation}

Cells were dissolved in $0.8 \mathrm{~mL}$ of $500 \mathrm{mM}$ sodium carbonate (pH 11) and homogenized with a 20-gauge needle and three 20-sec bursts of a sonicator. The sucrose concentration in cell extracts was adjusted to $45 \%$ by the addition of $0.8 \mathrm{~mL}$ of $90 \%$ sucrose prepared in MBS (25 $\mathrm{mM}$ Mes at $\mathrm{pH} 6.5,0.15 \mathrm{M} \mathrm{NaCl})$, and the extracts were placed at the bottom of an ultracentrifuge tube. A
$5 \%-35 \%$ discontinuous sucrose gradient was formed above $4 \mathrm{~mL}$ of $35 \%$ sucrose $/ 4 \mathrm{~mL}$ of $5 \%$ sucrose, both prepared in MBS containing $250 \mathrm{mM}$ sodium carbonate) and centrifuged at $45,000 \mathrm{rpm}$ for $16 \mathrm{~h}$ at $4^{\circ} \mathrm{C}$ in a SW55Ti rotor (Beckman). From the top of each gradient, a total of 11 fractions $(0.4 \mathrm{~mL}$ of each) were collected. Fractions were analyzed by immunoblot with antibodies detecting caveolin-1 (1:500 dilution; Becton Dickinson, catalog no. 610493), CHC (1:1000; Becton Dickinson, 610500), EEA1 (1:000; Novus Biologicals, NBP1-05962), PDGFR $\beta$ (1:1000; R\&D Systems, 3169), phospho-PDGFR $\beta$ (1:1000; R\&D System, 3161), ephrin-B2 (1:1000; Sigma, HAP008999), or VEGFR3 (1:1000; eBioscience, 14-5988).

\section{Immunoprecipitation}

Cells were lysed in $800 \mu \mathrm{L}$ of buffer $(25 \mathrm{mM}$ Tris- $\mathrm{HCl}$ at $\mathrm{pH} 7.5$, $150 \mathrm{mM} \mathrm{NaCl}, 1 \mathrm{mM}$ EGTA, $1 \%$ NP-40, $100 \mathrm{mM} \mathrm{NaF}, 10 \mathrm{mM}$ $\mathrm{Na}_{4} \mathrm{P}_{2} \mathrm{O}_{7}, 1 \mathrm{mM} \mathrm{Na} \mathrm{VO}_{4}$, protease inhibitor cocktail [1:100; Sigma, P2714]), and centrifuged. Aortae were lysed in buffer (0.1\% SDS, $1 \%$ Triton X-100, $150 \mathrm{mM} \mathrm{NaCl}, 25 \mathrm{mM}$ Tris- $\mathrm{HCl}$ at $\mathrm{pH} 7.5,5 \mathrm{mM}$ EDTA-NaOH at $\mathrm{pH} 8.5,100 \mathrm{mM} \mathrm{NaF}, 10 \mathrm{mM}$ $\mathrm{Na}_{4} \mathrm{P}_{2} \mathrm{O}_{7}, 1 \mathrm{mM} \mathrm{Na} \mathrm{VO}_{4}$, protease inhibitor cocktail [1:100; Sigma, P2714]) by using a tissue homogenizer (Ultra-Turrax, IKA) and centrifuged. Supernatants were precleared with uncoupled protein A or G beads (GE Healthcare) and incubated with antibodies for $1 \mathrm{~h}$ at $4^{\circ} \mathrm{C}$. Immunocomplexes were captured by adding $100 \mu \mathrm{L}$ of prewashed protein A/G and incubating for a further $2 \mathrm{~h}$ at $4^{\circ} \mathrm{C}$ on an orbital shaker. The beads were then collected by centrifugation, the supernatant was discarded, and beads were washed three times with lysis buffer. The beads were resuspended in $50 \mu \mathrm{L}$ of sample buffer.

\section{Rac1 pull-down assay}

Cells were lysed in buffer $(50 \mathrm{mM}$ Tris- $\mathrm{HCl}$ at $\mathrm{pH} 7.5,500 \mathrm{mM}$ $\mathrm{NaCl}, 1 \mathrm{mM}$ EGTA, $0.5 \% \mathrm{NP}-40,20 \mathrm{mM} \mathrm{MgCl}$, protease inhibitor cocktail [1:100; Sigma, P2714]) containing $400 \mu \mathrm{g}$ of PAKCRIB. The lysate was centrifuged at $13,000 \mathrm{rpm}$ for $2 \mathrm{~min}$ at $4^{\circ} \mathrm{C}$, and the supernatant was transferred to a new tube with glutathione beads. Aortae were lysed in buffer $(0.1 \%$ SDS, $1 \%$ Triton $\mathrm{X}-100,150 \mathrm{mM} \mathrm{NaCl}, 25 \mathrm{mM}$ Tris- $\mathrm{HCl}$ at $\mathrm{pH}$ 7.5, 5 mM EDTA$\mathrm{NaOH}$ at pH 8.5, $100 \mathrm{mM} \mathrm{NaF}, 10 \mathrm{mM} \mathrm{Na}_{4} \mathrm{P}_{2} \mathrm{O}_{7}, 1 \mathrm{mM} \mathrm{Na}_{3} \mathrm{VO}_{4}$, protease inhibitor cocktail [1:100; Sigma, P2714]) by using a tissue homogenizer (Ultra-Turrax, IKA) and centrifuged. Supernatants were combined with $400 \mu \mathrm{g}$ of PAK-CRIB and transferred to new tubes with glutathione beads. Tubes were then incubated for $1 \mathrm{~h}$ at $4^{\circ} \mathrm{C}$ with gentle rocking, centrifuged at $3000 \mathrm{rpm}$ for $30 \mathrm{sec}$, and washed with lysis buffer three times. Finally, beads were resuspended in $50 \mu \mathrm{L}$ of $1 \times$ SDS sample buffer.

\section{Automatic cell shape analysis}

Electroporation was performed by using the Amaxa Nucleofection system. Nonconfluent cells were trypsinized, washed in medium, and resuspended at a concentration of $1 \times 10^{6}$ cells per $100 \mu \mathrm{L}$ in an Amaxa Basic Nucleofector kit. Two micrograms of plasmid DNA was then mixed with $100 \mu \mathrm{L}$ of cells and placed in a cuvette. After electroporation by using setting T-030, cells were directly transferred to warm medium. Control or pEGFPtagged full-length Tiam1 transfected cells were seeded on sixwell dishes, fixed, and stained with Alexa Fluor 546 phalloidin (Invitrogen, 1:500), Alexa Fluor488-coupled anti-GFP antibody (Invitrogen, 1:500), and DAPI. The images were automatically analyzed by a custom-developed image-processing journal detecting the DAPI-stained nuclei followed by detection of cell outlines (using the Alexa Fluor 488 image) separating touching 
cells with watershed lines. Cells touching the border were rejected. A shape factor $\left(4 \times \pi \times\right.$ area/perimeter $\left.{ }^{2}\right)$ was calculated for each cell.

\section{Microarray and quantitative PCR analysis}

RNA was isolated from control and Efnb2 knockout cells after 3 $\mathrm{d}$ of culturing in IFN- $\gamma$-free cell medium using the RNAeasy kit (Qiagen) following the manufacturer's guidelines. Generation of gene expression profiles for control and Efnb2 knockout cells was carried out by the GeneChip microarray service at the Paterson Institute for Cancer Research using Affymetrix moe430A 2.0 chips.

For real-time PCR, cDNA synthesis was achieved from $500 \mathrm{ng}$ of total RNA by using the iScript cDNA synthesis kit (Bio-Rad) following the manufacturer's guidelines. Then, TaqMan gene expression assays (Applied Biosystems) for murine GAPDH and Tiam 1 were used in combination with TaqMan gene expression master mix.

\section{Quantification and image processing}

Volocity (Improvision), Photoshop CS, and Illustrator CS (Adobe) software was used for image processing without distorting or misrepresenting results. Data were based on at least three independent experiments or three mutant and control animals for each stage and result shown.

\section{Competing interest statement}

The authors declare that they have no competing financial interests.

\section{Acknowledgments}

We thank Alison Llyod for the plasmid encoding $\Delta$ Raf1-ER and John Collard for GFP-tagged, full-length Tiam1. The Max Planck Society, the German Research Foundation (programs SFB 629 and SPP 1190), graduate program CEDAD and IMPRS-MBM, the EMBO LTF program, and the Japan Society for the Promotion of Science have provided funding. A.N., M.N., and R.H.A. designed the study. A.N., M.N., C.J.T., and S.H, performed experiments. J.J.L. contributed reagents and discussed data. A.N., M.N., and R.H.A. wrote the manuscript.

\section{References}

Abella JV, Park M. 2009. Breakdown of endocytosis in the oncogenic activation of receptor tyrosine kinases. $A m I$ Physiol Endocrinol Metab 296: E973-E984.

Andrae J, Gallini R, Betsholtz C. 2008. Role of platelet-derived growth factors in physiology and medicine. Genes Dev 22: 1276-1312.

Batlle E, Henderson JT, Beghtel H, van den Born MM, Sancho E, Huls G, Meeldijk J, Robertson J, van de Wetering M, Pawson T, et al. 2002. $\beta$-Catenin and TCF mediate cell positioning in the intestinal epithelium by controlling the expression of EphB/ephrinB. Cell 111: 251-263.

Bethani I, Skanland SS, Dikic I, Acker-Palmer A. 2010. Spatial organization of transmembrane receptor signalling. EMBO $J$ 29: 2677-2688.

Bond M, Wu YJ, Sala-Newby GB, Newby AC. 2008. Rho GTPase, Rac1, regulates Skp2 levels, vascular smooth muscle cell proliferation, and intima formation in vitro and in vivo. Cardiovasc Res 80: 290-298.
Boucher P, Gotthardt M, Li WP, Anderson RG, Herz J. 2003. LRP: Role in vascular wall integrity and protection from atherosclerosis. Science 300: 329-332.

Chow JC, Condorelli G, Smith RJ. 1998. Insulin-like growth factor-I receptor internalization regulates signaling via the Shc/mitogen-activated protein kinase pathway, but not the insulin receptor substrate-1 pathway. J Biol Chem 273: 46724680.

Di Guglielmo GM, Le Roy C, Goodfellow AF, Wrana JL. 2003. Distinct endocytic pathways regulate TGF- $\beta$ receptor signalling and turnover. Nat Cell Biol 5: 410-421.

Finger EC, Lee NY, You HI, Blobe GC. 2008. Endocytosis of the type III transforming growth factor- $\beta$ (TGF- $\beta$ ) receptor through the clathrin-independent/lipid raft pathway regulates TGF- $\beta$ signaling and receptor down-regulation. I Biol Chem 283: 34808-34818.

Foo SS, Turner CJ, Adams S, Compagni A, Aubyn D, Kogata N, Lindblom P, Shani M, Zicha D, Adams RH. 2006. Ephrin-B2 controls cell motility and adhesion during blood-vessel-wall assembly. Cell 124: 161-173.

Forsberg K, Valyi-Nagy I, Heldin CH, Herlyn M, Westermark B. 1993. Platelet-derived growth factor (PDGF) in oncogenesis: Development of a vascular connective tissue stroma in xenotransplanted human melanoma producing PDGF-BB. Proc Natl Acad Sci 90: 393-397.

Fujita Y, Maruyama S, Kogo H, Matsuo S, Fujimoto T. 2004. Caveolin-1 in mesangial cells suppresses MAP kinase activation and cell proliferation induced by bFGF and PDGF. Kidney Int 66: 1794-1804.

Grunwald IC, Korte M, Adelmann G, Plueck A, Kullander K, Adams RH, Frotscher M, Bonhoeffer T, Klein R. 2004. Hippocampal plasticity requires postsynaptic ephrinBs. Nat Neurosci 7: 33-40.

Hansen CG, Nichols BJ. 2009. Molecular mechanisms of clathrinindependent endocytosis. J Cell Sci 122: 1713-1721.

Hayashi K, Takahashi M, Kimura K, Nishida W, Saga H, Sobue K. 1999. Changes in the balance of phosphoinositide 3-kinase/ protein kinase $\mathrm{B}(\mathrm{Akt})$ and the mitogen-activated protein kinases (ERK/p38MAPK) determine a phenotype of visceral and vascular smooth muscle cells. J Cell Biol 145: 727-740.

Keramati AR, Singh R, Lin A, Faramarzi S, Ye ZJ, Mane S, Tellides G, Lifton RP, Mani A. 2011. Wild-type LRP6 inhibits, whereas atherosclerosis-linked LRP6R611C increases PDGFdependent vascular smooth muscle cell proliferation. Proc Natl Acad Sci 108: 1914-1918.

Kumari S, Mg S, Mayor S. 2010. Endocytosis unplugged: Multiple ways to enter the cell. Cell Res 20: 256-275.

Lanahan AA, Hermans K, Claes F, Kerley-Hamilton JS, Zhuang ZW, Giordano FJ, Carmeliet P, Simons M. 2010. VEGF receptor 2 endocytic trafficking regulates arterial morphogenesis. Dev Cell 18: 713-724.

Lehti K, Rose NF, Valavaara S, Weiss SJ, Keski-Oja J. 2009. MT1MMP promotes vascular smooth muscle dedifferentiation through LRP1 processing. J Cell Sci 122: 126-135.

Lepore JJ, Cheng L, Min Lu M, Mericko PA, Morrisey EE, Parmacek MS. 2005. High-efficiency somatic mutagenesis in smooth muscle cells and cardiac myocytes in SM22 $\alpha$-Cre transgenic mice. Genesis 41: 179-184.

Lindahl P, Johansson BR, Leveen P, Betsholtz C. 1997. Pericyte loss and microaneurysm formation in PDGF-B-deficient mice. Science 277: 242-245.

Liu P, Ying Y, Ko YG, Anderson RG. 1996. Localization of platelet-derived growth factor-stimulated phosphorylation cascade to caveolae. J Biol Chem 271: 10299-10303.

Mertens AE, Pegtel DM, Collard JG. 2006. Tiam1 takes PARt in cell polarity. Trends Cell Biol 16: 308-316. 
Moes JJA, Zhou Y, Boonstra J. 2012. Co-localization of the PDGF $\beta$-receptor and actin during PDGF stimulation in mouse fibroblasts. ISRN Cell Biology 2012: doi: 10.5402/2012/ 568104.

Morcavallo A, Genua M, Palummo A, Kletvikova E, Jiracek J, Brzozowski AM, Iozzo RV, Belfiore A, Morrione A. 2012. Insulin and insulin-like growth factor II differentially regulate endocytic sorting and stability of insulin receptor isoform A. I Biol Chem 287: 11422-11436.

Muratoglu SC, Mikhailenko I, Newton C, Migliorini M, Strickland DK. 2010. Low density lipoprotein receptor-related protein 1 (LRP1) forms a signaling complex with plateletderived growth factor receptor- $\beta$ in endosomes and regulates activation of the MAPK pathway. I Biol Chem 285: 14308-14317.

Nakayama $M$, Nakayama A, van Lessen $M$, Yamamoto $H$, Hoffmann S, Drexler HC, Itoh N, Hirose T, Breier G, Vestweber D, et al. 2013. Spatial regulation of VEGF receptor endocytosis in angiogenesis. Nat Cell Biol 15: 249-260.

Olson LE, Soriano P. 2011. PDGFR $\beta$ signaling regulates mural cell plasticity and inhibits fat development. Dev Cell 20: 815-826.

Ostman A, Heldin CH. 2007. PDGF receptors as targets in tumor treatment. Adv Cancer Res 97: 247-274.

Pellet-Many C, Frankel P, Evans IM, Herzog B, JunemannRamirez M, Zachary IC. 2011. Neuropilin-1 mediates PDGF stimulation of vascular smooth muscle cell migration and signalling via p130Cas. Biochem J 435: 609-618.

Pitulescu ME, Adams RH. 2010. Eph/ephrin molecules-a hub for signaling and endocytosis. Genes Dev 24: 2480-2492.

Raines EW. 2004. PDGF and cardiovascular disease. Cytokine Growth Factor Rev 15: 237-254.

Sadowski L, Jastrzebski K, Kalaidzidis Y, Heldin CH, Hellberg C, Miaczynska M. 2013. Dynamin inhibitors impair endocytosis and mitogenic signaling of PDGF. Traffic 14: 725736.

Sakane H, Yamamoto H, Kikuchi A. 2010. LRP6 is internalized by Dkk1 to suppress its phosphorylation in the lipid raft and is recycled for reuse. J Cell Sci 123: 360-368.

Sawamiphak S, Seidel S, Essmann CL, Wilkinson GA, Pitulescu ME, Acker T, Acker-Palmer A. 2010. Ephrin-B2 regulates VEGFR2 function in developmental and tumour angiogenesis. Nature 465: 487-491.

Srinivas S, Watanabe T, Lin CS, William CM, Tanabe Y, Jessell TM, Costantini F. 2001. Cre reporter strains produced by targeted insertion of EYFP and ECFP into the ROSA26 locus. BMC Dev Biol 1: 4.

Sundberg C, Friman T, Hecht LE, Kuhl C, Solomon KR. 2009. Two different PDGF $\beta$-receptor cohorts in human pericytes mediate distinct biological endpoints. Am J Pathol 175: 171189.

Tallquist MD, French WJ, Soriano P. 2003. Additive effects of PDGF receptor $\beta$ signaling pathways in vascular smooth muscle cell development. PLOS Biol 1: E52.

Thiel G, Ekici M, Rossler OG. 2009. Regulation of cellular proliferation, differentiation and cell death by activated Raf. Cell Commun Signal 7: 8.

Uhrbom L, Hesselager G, Nister M, Westermark B. 1998. Induction of brain tumors in mice using a recombinant plateletderived growth factor B-chain retrovirus. Cancer Res 58: 5275-5279.

Vieira AV, Lamaze C, Schmid SL. 1996. Control of EGF receptor signaling by clathrin-mediated endocytosis. Science 274: 2086-2089.

Wang Y, Nakayama M, Pitulescu ME, Schmidt TS, Bochenek ML, Sakakibara A, Adams S, Davy A, Deutsch U, Luthi U, et al. 2010. Ephrin-B2 controls VEGF-induced angiogenesis and lymphangiogenesis. Nature 465: 483-486.

Yamamoto H, Sakane H, Michiue T, Kikuchi A. 2008. Wnt3a and Dkk1 regulate distinct internalization pathways of LRP6 to tune the activation of $\beta$-catenin signaling. Dev Cell 15: $37-48$.

Yoshimura K, Aoki H, Ikeda Y, Fujii K, Akiyama N, Furutani A, Hoshii Y, Tanaka N, Ricci R, Ishihara T, et al. 2005. Regression of abdominal aortic aneurysm by inhibition of c-Jun N-terminal kinase. Nat Med 11: 1330-1338.

Yu A, Rual JF, Tamai K, Harada Y, Vidal M, He X, Kirchhausen T. 2007. Association of Dishevelled with the clathrin AP-2 adaptor is required for Frizzled endocytosis and planar cell polarity signaling. Dev Cell 12: 129-141.

Zhou L, Takayama Y, Boucher P, Tallquist MD, Herz J. 2009. LRP1 regulates architecture of the vascular wall by controlling PDGFR $\beta$-dependent phosphatidylinositol 3-kinase activation. PLOS ONE 4: e6922.

Zou Y, Hu Y, Metzler B, Xu Q. 1998. Signal transduction in arteriosclerosis: Mechanical stress-activated MAP kinases in vascular smooth muscle cells (review). Int I Mol Med 1: 827-834. 


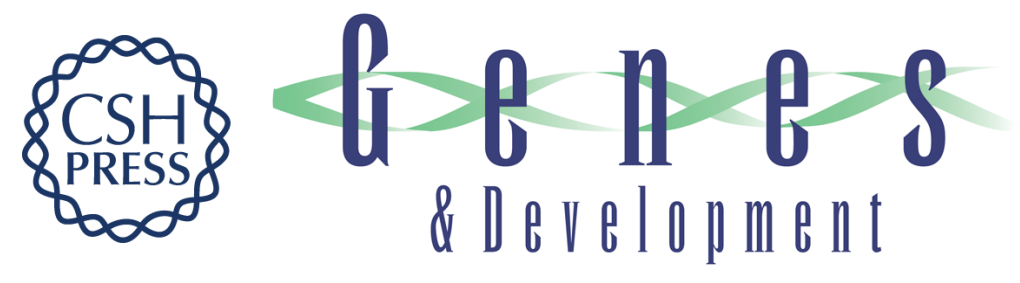

\section{Ephrin-B2 controls PDGFR $\beta$ internalization and signaling}

Akiko Nakayama, Masanori Nakayama, Christopher J. Turner, et al.

Genes Dev. 2013, 27:

Access the most recent version at doi:10.1101/gad.224089.113

Supplemental

Material

References

Creative

Commons

License

Email Alerting

Service
http://genesdev.cshlp.org/content/suppl/2013/12/02/27.23.2576.DC1

This article cites 46 articles, 19 of which can be accessed free at: http://genesdev.cshlp.org/content/27/23/2576.full.html\#ref-list-1

This article, published in Genes \& Development, is available under a Creative Commons License (Attribution-NonCommercial 3.0 Unported), as described at http://creativecommons.org/licenses/by-nc/3.0/.

Receive free email alerts when new articles cite this article - sign up in the box at the top right corner of the article or click here.

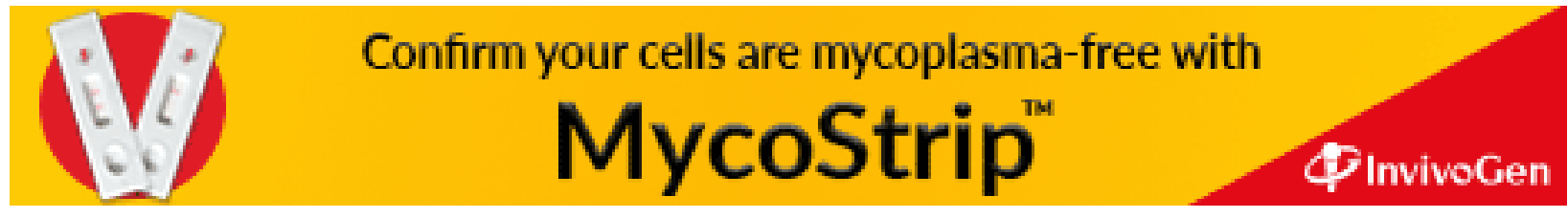

